\title{
Sewage biogas efficient purification by means of lignocellulosic waste- based activated carbons
}

\author{
Eric Santos-Clotas ${ }^{1}$, Alba Cabrera-Codony ${ }^{1}$, B. Ruiz ${ }^{2}$, E. Fuente ${ }^{2}$, Maria J Martín ${ }^{1 *}$ \\ ${ }^{1}$ LEQUIA. Institute of Environment. University of Girona, Campus Montilivi, Maria \\ Aurèlia Capmany 69, E-17003 Girona. Catalonia. Spain \\ ${ }^{2}$ Biocarbon and Sustainability Group (B\&S); Instituto Nacional del Carbon (INCAR), \\ CSIC. C/ Francisco Pintado Fe, 26, 33011 Oviedo, Spain
}

*Corresponding author: E-mail address: maria.martin@udg.edu, Tel: +34972419261

\begin{abstract}
The present paper evaluates the efficiency of sustainable activated carbons obtained from the valorization of lignocellulosic waste in removing siloxanes and volatile organic compounds for the purification of anaerobic digester biogas.

Pyrolized and non-pyrolized lignocellulosic residues generated in food and wood industries were used as precursor materials to obtain experimental adsorbents by a chemical activation process using several activating agents. The highest porosity was obtained by non-pyrolized residue activated by $\mathrm{K}_{2} \mathrm{CO}_{3}$ at $900{ }^{\circ} \mathrm{C}$.

The performance of the experimental materials was compared with that of commercial activated carbons in gas adsorption tests of siloxanes (octamethylcyclotetrasiloxane and hexamethyldisiloxane) and volatile organic compounds (toluene and limonene).

The waste-based activated carbons developed in this work proved to be more efficient for the removal of both siloxanes and VOCs than the commercial samples in most of the conditions tested. Adsorption capacities correlated with porosity, while the more relevant pore size depends on the adsorbate.
\end{abstract}




\section{Keywords}

Lignocellulosic waste; Sustainable activated carbon; Siloxanes adsorption; VOCs adsorption; Biogas upgrading

\section{Introduction}

The anaerobic digestion of organic matter in landfills and wastewater treatment plants (WWTP) leads to the formation of biogas that can be used in energy recovery systems for heat and electricity production. This gas is not only composed by $\mathrm{CH}_{4}$ (40-60\%), but it also contains $\mathrm{CO}_{2}(40-55 \%)$ and other compounds in concentrations under $2 \%$ (i.e. $\mathrm{H}_{2} \mathrm{~S}$ ). Moreover, it comprises a wide spectrum of trace pollutants including alkanes, aromatic hydrocarbon compounds such as toluene, and odor-causing terpenes such as limonene. Besides these, siloxanes are of special concern.

Siloxanes are a group of silicon-containing compounds that present many advantageous properties (water repelling, high compressibility, high thermal stability, etc.) that make them interesting in many industrial processes or applications. Thus, siloxanes can be found in cosmetics, detergents, shampoos and many more everyday products (Dewil et al., 2006) ending up in urban wastewater treatment plants. Since they present high affinity for the sludge flocs throughout the conventional biological wastewater treatment process (Neyens et al., 2004), siloxanes reach the anaerobic digesters where the biogas is formed and due to the elevated temperatures they are volatilized.

During biogas combustions siloxanes are converted into silicon dioxide, which has abrasive properties to the energy recovery units, decreasing its efficiency and promoting gas pollutant emissions (Ajhar et al., 2010). 
Activated carbon (AC) is the most widely used adsorbent support in filters for biogas upgrading to remove siloxanes prior to biogas combustion, having demonstrated high removal efficiencies (Matsui and Imamura, 2010). The major drawback of this technology is the high operational costs due to the carbon replacement when the adsorption beds are exhausted (Cabrera-Codony et al., 2015).

Traditional activated carbons are commonly produced from really expensive and nonrenewable feedstocks such as coal, lignite or anthracite (Tan et al., 2017). The current economic pressure over these materials has pushed the market to look for alternative precursors for producing activated carbon. Low-cost and sustainable bioresources like biomass residues have gained attention in the recent years. Nowadays, loads of scientific studies have suggested the use of residues from the food, weather or automobile industries as precursor materials to produce activated carbons (FerreraLorenzo et al., 2014a; Gil et al., 2014; Mui et al., 2010; Ros et al., 2006; Ruiz et al., 2017).

In this context, the valorization of the biomass is gaining great importance and there is a significant number of scientific publications where lignocellulosic waste is activated in order to obtain porous activated carbons (Cagnon et al., 2009; Ioannidou and Zabaniotou, 2007; Suhas et al., 2016). A wide spectrum of agricultural residues and lignocellulosic materials have already been investigated as precursors for ACs: coconut shells, olive stones and pistachio-nuts among many others (Kailappan et al., 2000; Li et al., 2008; Lua and Yang, 2005; Spahis et al., 2008). Some publications report on the effectiveness of lignocellulosic-based ACs for water treatment applications such as the removal of dyes, metals or pharmaceuticals (Liu et al., 2018; Wang et al., 2013; Zhang et al., 2018) as well as $\mathrm{CO}_{2}$ capture (Zhang et al., 2014). 
Regarding the activation procedures, the use of chemicals is preferred over physical activation since it requires lower temperatures and achieves higher yields and surface areas (Budinova et al., 2006). Moreover, the chemical activation is carried out in one single step and obtains greatly developed microporosities (Yahya et al., 2015). Several activating agents have been reported to be effective in the activation of various agricultural wastes. For instance, from a $\mathrm{K}_{2} \mathrm{CO}_{3}$ activation in palm shell based carbon a surface area of $1170 \mathrm{~m}^{2} \mathrm{~g}^{-1}$ was obtained (Adinata et al., 2007). KOH activation in carbon produced from hazelnut bagasse reached a surface area of $1642 \mathrm{~m}^{2} \mathrm{~g}^{-1}$ and 0,96 $\mathrm{cm}^{3} \mathrm{~g}^{-1}$ of total pore volume (Demiral et al., 2008).

Adsorption is a commonly accepted technique to remove pollutants effectively from both aqueous and gaseous media. Understanding the basic adsorption/desorption reactions as well as the catalytic processes involved in many cases is of great interest to predict its behavior. Thus, adsorption models are useful tools for understanding the adsorbate's behavior during adsorption processes and its interaction with the adsorbent material (Gimbert et al., 2008).

The objective of the present work is to obtain activated carbons capable of removing siloxanes and volatile organic compounds (VOCs) from the valorization of lignocellulosic waste as precursor material. The resulting materials will be evaluated in adsorption equilibrium experiments to compare their performance with the commercial ACs currently used for biogas upgrading and prove the efficiency of this residue valorization.

\section{Materials and methods}




\subsection{Activated carbons}

A set of four chemically activated carbons were obtained experimentally. The activation procedure was the following: $3 \mathrm{~kg}$ of lignocellulosic waste generated in a food industry were cleaned and dried at $60{ }^{\circ} \mathrm{C}$. The resulting sample was grounded to a particle size below $5 \mathrm{~mm}$.

Part of the grounded sample was pyrolyzed in a tubular furnace Carbolite CTF 12/65/550. Pyrolysis conditions were selected according to previous experience (Ferrera-Lorenzo et al., 2014a; Gil et al., 2012) and were $150 \mathrm{~mL} \mathrm{~min}^{-1}$ of $\mathrm{N}_{2}$ flow, a heating rate of $5{ }^{\circ} \mathrm{C} \mathrm{min}^{-1}$ up to $750^{\circ} \mathrm{C}$ and maintained at this temperature for $60 \mathrm{~min}$. Both the cleaned lignocellulosic waste and its pyrolyzed version were employed as precursors for the experimental activated carbons.

Prior to the activation process, the precursor and the activating agent were mixed in solid state in different ratios $(0.5: 1$ and 1:1) as described in Table 1. Such reagents and concentration ratios were selected based in previous works (Ferrera-Lorenzo et al., 2014b), considering that ratios lower than $0.5: 1$ do not achieve high textural development and ratios higher than 1:1 result in low material yields (Ruiz et al., 2017). The thermochemical process of both $\mathrm{KOH}$ and $\mathrm{K}_{2} \mathrm{CO}_{3}$ activation was carried out in the aforementioned furnace at the activating temperature and nitrogen flow rate summarized in Table 1.

The representativeness of the final adsorbent is guaranteed since each sample is the result of five subsamples produced independently in equal conditions. Such subsamples are homogenized and processed with the cleaning step. 
After chemical activation, the resulting adsorbents were washed with hydrochloric acid solution (5 M) and successively washed with deionized water (Milli-Q) for eliminating residual activation products that might block the obtained porosity. The last step consisted in drying the samples at $105^{\circ} \mathrm{C}$ overnight.

Besides the experimental samples, three commercial activated carbons from different precursors were selected for this study. Their origins and activation agents are summarized in Table 1.

\subsection{Adsorbents characterization}

\subsubsection{Chemical characterization}

The ash content and moisture of all the ACs was obtained following the UNE 32004 norm and the UNE 33002 norm, respectively. Therefore, samples were calcined in a muffle at a temperature of $815^{\circ} \mathrm{C}$ for 1 hour in order to obtain the ash content. The moisture of the sample was determined based on the weight loss after $1 \mathrm{~h}$ at $105^{\circ} \mathrm{C}$.

Elemental analysis was carried out using a LECO CHN-2000 equipment for determining the carbon, hydrogen and nitrogen contents. LECO S-144-DR instrument (LECO Corporation, United States) was used for analyzing the sulphur content. Oxygen content was calculated as the difference.

\subsubsection{Textural characterization}

Helium pycnometry was carried out on a Micrometrics AccuPyc 1330 pycnometer in order to determine the real density $\left(\rho_{\mathrm{He}}\right)$ of the materials.

Adsorption-desorption equilibrium isotherms of $\mathrm{N}_{2}$ at $77 \mathrm{~K}$ and $\mathrm{CO}_{2}$ at $273 \mathrm{~K}$ were volumetrically obtained by a Micrometrics ASAP 2420 and a Quantachrome NOVA 4000 instrument. Prior to adsorption experiments for both gases, all the carbons were 
outgassed under vacuum at $120^{\circ} \mathrm{C}$ overnight for the removal of moisture and other vapors and gases.

The specific surface area $\left(\mathrm{S}_{\mathrm{BET}}\right)$ and the total pore volume $\left(\mathrm{V}_{\mathrm{TOT}}\right)$ at a relative pressure of 0.99 were obtained by fitting the nitrogen adsorption data to the BET equation (Brunauer et al., 1940, 1938). By applying the density functional theory (DFT) model to the $\mathrm{N}_{2}$ isotherms, and assuming slit-shaped pore geometry (Olivier et al., 1994), we obtained the pore size distribution; microporosity $\left(\mathrm{V}_{\mathrm{umi}}<0.7 \mathrm{~nm}\right)$, medium size micropore volume $\left(\mathrm{V}_{\mathrm{mmi}} 0.7-2 \mathrm{~nm}\right)$ and mesoporosity $\left(\mathrm{V}_{\mathrm{me}} 2-50 \mathrm{~nm}\right)$.

The narrow microporosity was studied from the $\mathrm{CO}_{2}$ adsorption isotherms. The micropore volume $\left(\mathrm{W}_{0}\right)$ and the characteristic energy $\left(\mathrm{E}_{0}\right)$ were calculated from the application of the Dubinin-Radushkevich equation (assuming the density of $\mathrm{CO}_{2}$ adsorbed as $1.023 \mathrm{~g} \mathrm{~cm}^{-3}$ and the $\beta$ parameter as 0.36). The Dubinin-Radushkevich surface $\left(S_{\mathrm{DR}}\right)$ was obtained from the micropore volume. The mean micropore size $(\mathrm{L})$ was evaluated from the expression $\mathrm{L}=10.8 /\left(\mathrm{E}_{0}-11.4\right)$ (Stoeckli and Ballerini, 1991).

\subsubsection{Morphology}

A scanning electron microscope (SEM) ZEISS DMS-942 (ZEISS, United States) equipped with an energy-dispersive X-ray analysis system (Link-Isis II) was used to examine the morphology of the materials. Prior to observation, all the samples were covered with iridium in order to reduce the charging of the materials to obtain improved pictures.

\subsection{Adsorption equilibrium experiments}

The target compounds selected for carrying out the adsorption equilibrium experiments of this study were toluene, limonene and the siloxanes octamethylcyclotetrasiloxane 
(D4) and hexamethyldisiloxane (L2). Their main physical properties are gathered on Table 2. Critical diameters of the adsorbates can be found in previous research (Cabrera-Codony et al., 2018). All the reagents were purchased in liquid form (>95\%) from Sigma Aldrich (USA).

The adsorption experiments were carried out at $25 \pm 2{ }^{\circ} \mathrm{C}$. The adsorption equilibrium of each compound was studied individually using 10-70 $\mathrm{mg}$ of powdered activated carbon in $20-\mathrm{cm}^{3}$ vials sealed with PTFE septa weighted by an analytical balance (XSR105 Mettler Toledo, USA). Liquid volumes of $4 \mu \mathrm{L}$ of the target compound were successively injected on the vial and agitated in an orbital mixer for $24 \mathrm{~h}$ in a thermostatic chamber at $25^{\circ} \mathrm{C}$ to reach adsorption equilibrium. Preliminary tests showed that adsorption equilibrium was reached after $24 \mathrm{~h}$ (data not shown). After this time, the concentration of the target compound $\left(\mathrm{C}_{\mathrm{e}}\right)$ in the vial headspace was analyzed by a gas chromatograph coupled to a mass spectrometry detector (7980B series GCMSD, Agilent Technologies) and equipped with a PAL auto sampler system with a headspace tool, and a capillary column HP-5ms Ultra Inert (Agilent Technologies). Calibration was carried out diluting commercial standards of siloxanes (D4 and L2) and VOCs (toluene and limonene) in tetrahydrofuran (THF, 99\% purity) and injection to the $20-\mathrm{cm}^{3}$ vials.

The amount of target compound adsorbed at equilibrium, $\mathrm{x} / \mathrm{M}\left(\mathrm{mg} \mathrm{g}^{-1}\right)$, was calculated by Eq. 1

$$
\frac{x}{M}=\left(\frac{C_{0}-C_{e}}{W}\right) V
$$

Eq. 1

where $\mathrm{C}_{0}$ and $\mathrm{C}_{\mathrm{e}}$ are the initial and equilibrium target concentrations $\left(\mathrm{mg} \mathrm{m}^{-3}\right)$; $\mathrm{W}$ is the mass of carbon $(\mathrm{g})$; and $\mathrm{V}$ is the volume of the vial $\left(\mathrm{m}^{3}\right) . \mathrm{C}_{0}$ was calculated according to 
the amount of target compound injected on the $20-\mathrm{cm}^{3}$ vials, which was confirmed by weighing the vial before and after the liquid injection.

Static adsorption tests for each activated carbon and adsorbate were performed by triplicate (coefficient of variation $<15 \%$ ) and the adsorption capacity considered was the average value of the three tests.

\subsection{Spend carbon analysis}

For studying the siloxanes transformation in contact with the carbons in this study, a representative mass of $30 \mathrm{mg}$ of powdered activated carbon samples were placed in 20$\mathrm{cm}^{3}$ vials and $6 \mu \mathrm{L}$ of reagent D4 or L2 were injected through the septa of the vial. After $24 \mathrm{~h}$ of contact for adsorption/transformation to happen, $10 \mathrm{~mL}$ of THF were injected to the vials, vortexed for 2 min and shaken in an orbital mixer for $30 \mathrm{~min}$. The resulting suspensions were filtered through $0.45 \mu \mathrm{m}$ and the liquid suspensions were analyzed by GC-MS following the methodology described in previous work (Cabrera-Codony et al., 2017). Spend carbon experiments were performed in triplicate (coefficient of variation $<12 \%)$.

\section{Results and discussion}

\subsection{Chemical characterization}

The lignocellulosic waste used in the preparation of the activated carbons had a high carbon content (45.83\%) and a low ash content (3.66\%). After the pyrolysis process, the char obtained presented an increase in both parameters $(82.15 \%$ and $8.10 \%$ carbon and ash content, respectively). Thus, both pyrolyzed and non-pyrolyzed samples presented a chemical composition, i.e. carbon content, appropriated to be used as precursors for obtaining activated carbon. 
The elemental analysis and ash content of both the experimental and commercial activated carbons is presented in Table 3. The experimental carbons displayed higher carbon contents $(>94 \%$ vs $<90 \%)$ and lower ash content $(<2 \%$ vs $>7 \%)$ than the commercial ACs. Similar C contents have been reported for activated carbons obtained from the valorization of other residues such as chestnut shells (Ruiz et al., 2017) and algae meal waste (Ferrera-Lorenzo et al., 2014a). The commercial $\mathrm{H}_{3} \mathrm{PO}_{4}$-activated carbon AC5 stood out for its relatively low carbon (80.15\%) and high hydrogen $(2.31 \%)$ and oxygen $(7.37 \%)$ contents among the rest of the materials. Nitrogen content was found greater for the experimental carbons $(>1 \%)$ than the commercials $(<0.7 \%)$, while sulphur content was under $0.5 \%$ for all the materials.

\subsection{Textural characterization}

$\mathrm{N}_{2}$ and $\mathrm{CO}_{2}$ adsorption isotherms are shown in Fig. $1 \mathrm{~A}$ and $1 \mathrm{~B}$, respectively. According to the IUPAC classification (Thommes et al., 2015), AC5 and AC7 displayed a type Ib $\mathrm{N}_{2}$ adsorption isotherm which indicated the predominance of wider micropores. Moreover, AC5 presented a hysteresis cycle and a more defined slope from low relative pressures, which indicates the presence of mesopores. On the other hand, all the experimental materials and the commercial AC6 exhibited a type Ia $\mathrm{N}_{2}$ adsorption isotherm, characteristic of materials dominated by narrow micropores. $\mathrm{CO}_{2}$ adsorption isotherms further confirmed the high presence of narrow micropores within the experimental ACs.

The pore size distribution of the materials calculated by the DFT method is gathered in Table 4. These results show that, while most experimental materials are fundamentally microporous, the commercial ACs have lower contribution of narrow micropores. The greatest adsorption in medium micropores $\left(\mathrm{V}_{\mathrm{mmi}}\right.$ : volume corresponding to pore width 
0.7-2 $\mathrm{nm}$ ) is observed in the commercial AC5 and the experimental AC2. On the other hand, mesoporosity contribution, indicated by the hysteresis loop and steep slope in $\mathrm{N}_{2}$ isotherm, is practically negligible in most samples except AC5.

$\mathrm{CO}_{2}$ adsorption data further confirmed that the experimental ACs had a major contribution of narrow micropores. From Table 4 it can be observed that AC4 was the most outstanding material in terms of narrow microporosity $\left(0.732 \mathrm{~cm}^{3} \mathrm{~g}^{-1}\right)$ and DR surface $\left(1899 \mathrm{~m}^{2} \mathrm{~g}^{-1}\right)$. Commercial samples had a clear minor contribution of such microporosity being the steam-activated coal-based AC7 the poorest material.

\subsection{Effect of the activation conditions on the carbon development}

In some cases, lignocellulosic wastes undergo a pyrolysis process for the production of other products such as liquid bio-oils and fuel gas. In these scenarios, the pyrolized waste is obtained as a char residue which can be regarded as a potential precursor material for activated carbon (Bridgwater, 2012). However, pyrolyzed waste presents an ordered structure that requires more reactive chemicals for its activation than nonpyrolyzed lignocellulosic waste.

Alkali activating agents $\mathrm{K}_{2} \mathrm{CO}_{3}$ and $\mathrm{KOH}$ have been widely used and reported in the activation of carbonaceous materials. They were selected in this study due to previous experience on the activation of lignocellulosic waste (Ruiz et al., 2015). Generally, it is known that $\mathrm{KOH}$ is a more reactive agent than $\mathrm{K}_{2} \mathrm{CO}_{3}$ at a same activating temperature. For this reason, $\mathrm{K}_{2} \mathrm{CO}_{3}$ was the activating agent selected for the non-pyrolyzed samples (AC1 and $\mathrm{AC} 2)$ and $\mathrm{KOH}$ for the pyrolyzed samples (AC3 and $\mathrm{AC} 4)$.

The temperature in the activation process is a critical parameter in the development of the porosity. Ferrera-Lorenzo et al., (2014b) studied the temperature effect $\left(500{ }^{\circ} \mathrm{C}-\right.$ 
$900{ }^{\circ} \mathrm{C}$ ) to activate a macro algae residue using $\mathrm{KOH}$ concluding that higher temperatures led to higher yields in this range.

In the working conditions of this study, the non-pyrolyzed carbons activated with $\mathrm{K}_{2} \mathrm{CO}_{3}$ demonstrated higher BET surface area and total pore volume than the pyrolyzed materials (see Table 4). Within the pyrolyzed samples, which were activated at $900{ }^{\circ} \mathrm{C}$ the textural development increased significantly with the $\mathrm{KOH}$ concentration $(\mathrm{AC} 3<\mathrm{AC} 4)$. As a result of the pyrolysis prior to the activation process, the original structure of the biomass is highly preserved even at the highest $\mathrm{KOH}$ concertation used. SEM images of AC3 show such preservation, which enables a more ordered development of the structure than those observed in other materials.

Regarding the non-pyrolyzed samples, $\mathrm{AC} 1\left(1 / 1,850^{\circ} \mathrm{C}\right)$, which was obtained using a higher amount of activating agent than $\mathrm{AC} 2\left(0.5: 1,900^{\circ} \mathrm{C}\right)$, did not demonstrate a major textural development. Thus, temperature is critical in the activation of these samples. In the activation conditions of $\mathrm{AC} 2$, the largest mesoporosity was developed.

$\mathrm{K}_{2} \mathrm{CO}_{3}$ is an agent with a high capacity to react with the mineral matter of the biomass, leading to the formation of soluble compounds that will be removed during the postcleaning step of the adsorbent. For this reason, the ash content of both AC1 and AC2 is the lowest of the set of carbons considered (Table 3). Accordingly, mineral matter (white shiny parts) cannot be observed in the SEM of AC1.

On the contrary, AC6 is a commercial anthracite-based carbon physically activated with steam. Within this type of activation, the mineral matter remains in the resulting adsorbent material, as in the $\mathrm{H}_{3} \mathrm{PO}_{4}$-activated $\mathrm{AC} 5$, which is denoted by the ash content and the SEM images. Moreover, a major difference observed in the AC6 SEM captions 
in comparison with the other materials commented above, is the absence of cavities and channels. This fact might be indicative of a low porosity development, agreeing with the textural data in Table 4.

\subsection{Siloxanes and VOCs adsorption equilibrium at $25^{\circ} \mathrm{C}$}

Fig. 2 shows the gas uptakes $(\mathrm{x} / \mathrm{M})$ obtained in static adsorption tests at different equilibrium concentrations $\left(\mathrm{C}_{\mathrm{e}}\right)$ for both siloxanes (D4 and L2) and VOCs (toluene and limonene) for the whole set of carbons. In general terms, it can be observed that higher uptakes were achieved by lignocellulosic carbons rather than anthracite and coal-based materials. The best candidate adsorbing D4 was the commercial $\mathrm{H}_{3} \mathrm{PO}_{4}$-activated AC5, whereas the experimental material AC2 stood up in the adsorption of all the pollutants.

Adsorption characteristics were investigated by fitting the experimental data to three two-parameter models (Langmuir, Freundlich and Dubinin-Radushkevich) and to the three-parameter Dubinin-Astakhov (DA) equation. The best fit was obtained with the latter, expressed as Eq. 2,

$\left.W=W_{0} \cdot e^{\left[-\left(\frac{R T \ln \left(P_{0} / P\right.}{E}\right)\right)^{n}}\right] \quad$ Eq. 2

where $\mathrm{W}$ is the mass of adsorbate adsorbed per mass of $\mathrm{AC}\left(\mathrm{mg} \mathrm{g}^{-1}\right), \mathrm{W}_{0}$ is the maximum mass of adsorbate adsorbed in the micropores $\left(\mathrm{cm}^{-3} \mathrm{~g}^{-1}\right)$, E is the adsorption energy $\left(\mathrm{kJ} \mathrm{mol}^{-1}\right), \mathrm{T}$ is the temperature $(\mathrm{K}), \mathrm{R}$ the universal gas constant $(0.008314 \mathrm{~kJ}$ $\mathrm{K}^{-1} \mathrm{~mol}^{-1}$ ), $\mathrm{P}$ vapor pressure at saturation and $\mathrm{P}_{0}$ adsorbate partial pressure $(\mathrm{mm} \mathrm{Hg}$ ), and $\mathrm{n}$ is an exponent that can range from 1 to 5 (Harry Marsh, 2006). $\mathrm{n}$ parameter equal or above 3 represents molecular sieve carbons dominated by narrow micropores, whereas $\mathrm{n}$ values below 2 represent microporous carbons with wider pore size 
distribution (Dastgheib and Karanfil, 2005; Rodríguez-Mirasol et al., 2005). DA fitting data is shown in lines in Fig. 2.

Maximum adsorption capacities (x/M) calculated for each adsorbate are presented in Table 5, together with the $\mathrm{n}, \beta$ and $\mathrm{r}^{2}$ resulting from the DA fitting. L2 adsorption capacities calculated ranged from 220 (AC3) to $438 \mathrm{mg} \mathrm{g}^{-1}$ (AC2), while D4 ranged from 185 (AC3) to $577 \mathrm{mg} \mathrm{g}^{-1}$ (AC5). D4 presented the highest adsorption capacities from the compounds considered in this study, probably because it is the highest molecular weight molecule. Nam et al., (2013) reported similar adsorption capacities of siloxanes within adsorption equilibrium experiments fitted to Langmuir-Freundlich isotherm model using commercial activated carbons.

Thus, the highest $\mathrm{x} / \mathrm{M}$ calculated for siloxanes corresponded to $\mathrm{AC} 1, \mathrm{AC} 2$ and $\mathrm{AC} 5$, all of them lignocellulosic-based activated carbons with chemical activation, and the performance of the experimental material $\mathrm{AC}$ was comparable in terms of efficiency to the best commercial carbon tested.

On the other hand, toluene capacities calculated range from 192 (AC6) to $417 \mathrm{mg} \mathrm{g}^{-1}$ (AC2), whereas limonene capacities range from 275 (AC6) to $446 \mathrm{mg} \mathrm{g}^{-1}$ (AC2). Toluene adsorption capacities ranging $62-183 \mathrm{mg} \mathrm{g}^{-1}$ have been reported from adsorption data fitted to Langmuir isotherm model of several commercial activated carbons (Yang et al., 2018). Lillo-Ródenas et al., (2005) reported toluene adsorption capacities that are in good agreement with our study using experimental activated carbons impregnated with different chemicals.

Hence, the experimental carbon AC2 resulted the carbon with the highest efficiency to remove VOCs of the set studied in this work. 


\subsection{Importance of the texture}

We investigated the relationship of the adsorption capacities calculated by DA fitting (Table 5) with textural characterization (Table 4). In general terms, there was a positive correlation between the textural development of the carbons and their adsorption capacity for all adsorbates. Ultramicropore volume did not relate with the adsorption capacity for any of the compounds studied due to their molecular sizes, larger than ultramicropore width $(<0.7 \mathrm{~nm})$, which was observed by other studies working with $\mathrm{D} 4$ (Cabrera-Codony et al., 2014). The best lineal correlations are shown in Fig. 3, i.e. total pore volume and the total micropore volume $\left(\mathrm{V}_{\mathrm{mi}}\right)$.

As denoted by the different slopes in the lineal correlations obtained, experimental and commercial carbons showed different trends. Commercial activated carbons presented larger contribution of mesopores in their total porosity. While AC2 is the experimental sample with the most significant presence of mesopores, it was still lower than commercials.

D4 adsorption is known to occur within wide micropores and mesopores (Nam et al., 2013; Oshita et al., 2010). While L2 critical diameter is smaller, it is still preferently adsorbed in narrower mesoporosity (Cabrera-Codony et al., 2018). Thus, D4 and L2 adsorption capacities were correlated with the total volume of pores for the whole set of carbons (Fig. 3 A,C). When studying the effect of microporosity, experimental and commercial materials presented different correlations due to their difference on the mesoporosity contribution (Fig. 3 B,D).

On the other hand, adsorption of toluene and limonene is not ruled out by mesoporosity, but microporosity is the major contributor as pointed out in other studies (Qian et al., 2015). Thus, similar tendency between the two groups of carbons regarding VOCs 
adsorption was found out when considering micropore volume (Fig. $3 \mathrm{~F}, \mathrm{H}$ ), and it is observed that for the same total pore volume experimental samples performed the best (Fig. 3 E,G).

\subsection{Siloxane transformation}

It has been previously observed that the acidic sites on the activated carbons' surface may lead to the transformation of siloxanes into linear by-products, known as $\alpha-\omega$ silanediols (Cabrera-Codony et al., 2018; Jiang et al., 2016). We studied the catalytic activity of the samples towards D4 and L2 by extracting the adsorbed compounds and transformation products in THF suspensions.

In the extracts of the D4-spend carbon samples, other cyclic siloxanes (D5, dodecamethylcyclohexasiloxane (D6) and tetradecamethylcycloheptasiloxane (D7)) were found along with small amounts of $\alpha$ - $\omega$-silanediols (see Figure 4B). The highest D4 recoveries were found for the steam-activated carbons AC6 and AC7 reaching 94\% in both cases. D4 hydrolysis and condensation reactions take place due to the oxygenated groups in the surface of the activated carbons (Cabrera-Codony et al., 2014). In agreement with the elemental analysis (Table 3), AC6 and AC7 are the carbons with lowest oxygen content. On the contrary, a significant presence of $\alpha-\omega$ silanediols was found in the extract of the acid activated AC5, similar behavior as those of the experimental ACs in this study.

On the other hand, in the THF extractions of L2-spend samples, no transformation products were found, and more than $85 \%$ of the L2 was recovered from most of the carbon samples (see Fig. 4A), denoting that L2 transformation reactions do not take place on the surface of the studied materials. 


\section{Conclusions}

The experimental carbons developed in this study performed better than commercial samples for the adsorption of L2 and toluene (up to 438 and $417 \mathrm{mg} \mathrm{g}^{-1}$, respectively), and as good as the best commercial samples for limonene and D4. Thus, activation through $\mathrm{K}_{2} \mathrm{CO}_{3}$ of lignocellullosic wastes is an effective process for obtaining feasible adsorbents for biogas purification.

Pyrozyled samples activated by $\mathrm{KOH}$ led to carbons with lower porosities than nonpyrolyzed ones. Yet they presented performances comparable with steam ACs commercialized for biogas upgrading. AC4, activated using higher concentration of $\mathrm{KOH}$ presented a significant microporosity development, facilitating the uptake of VOCs.

\section{Acknowledgements}

This work was funded by MINECO - Spain (CTQ2014-53718-R) co-funded by FEDER and University of Girona. Eric Santos-Clotas thanks Universitat de Girona for his predoctoral grant (IFUdG-2015/51). Alba Cabrera-Codony acknowledges support from the European Union's Horizon 2020 research and innovation programme under the Marie Skłodowska-Curie grant agreement No 712949 (TECNIOspring PLUS) and from the Agency for Business Competitiveness of the Government of Catalonia (TECSPR161-0045). LEQUIA has been recognized as consolidated research group by the Catalan Government (2017-SGR-1552).

E-supplementary data of this work can be found in online version of the paper. 


\section{References}

1. Adinata, D., Wan Daud, W.M.A., Aroua, M.K., 2007. Preparation and characterization of activated carbon from palm shell by chemical activation with $\begin{array}{lll}\text { K2CO3. } & \text { Bioresour. } & \text { Technol. }\end{array}$ https://doi.org/10.1016/J.BIORTECH.2005.11.006

2. Ajhar, M., Travesset, M., Yüce, S., Melin, T., 2010. Siloxane removal from landfill and digester gas - A technology overview. Bioresour. Technol. 101, 2913-2923. https://doi.org/10.1016/j.biortech.2009.12.018

3. Bridgwater, A. V., 2012. Review of fast pyrolysis of biomass and product upgrading. Biomass and Bioenergy 68-94. https://doi.org/10.1016/j.biombioe.2011.01.048

4. Brunauer, S., Deming, L.S., Deming, W.E., Teller, E., 1940. On a Theory of the van der Waals Adsorption of Gases. J. Am. Chem. Soc. 62, 1723-1732. https://doi.org/10.1021/ja01864a025

5. Brunauer, S., Emmett, P.H., Teller, E., 1938. Adsorption of Gases in Multimolecular Layers. J. Am. Chem. Soc. 60, 309-319. https://doi.org/10.1021/ja01269a023

6. Budinova, T., Ekinci, E., Yardim, F., Grimm, A., Björnbom, E., Minkova, V., Goranova, M., 2006. Characterization and application of activated carbon produced by H3PO4 and water vapor activation. Fuel Process. Technol. 87, 899-905. https://doi.org/10.1016/j.fuproc.2006.06.005

7. Cabrera-Codony, A., Georgi, A., Gonzalez-Olmos, R., Valdés, H., Martín, M.J., 2017. Zeolites as recyclable adsorbents/catalysts for biogas upgrading: Removal of octamethylcyclotetrasiloxane. Chem. Eng. J. 307. 
https://doi.org/10.1016/j.cej.2016.09.017

8. Cabrera-Codony, A., Gonzalez-Olmos, R., Martín, M.J.J., 2015. Regeneration of siloxane-exhausted activated carbon by advanced oxidation processes. J. Hazard. Mater. 285. https://doi.org/10.1016/j.jhazmat.2014.11.053

9. Cabrera-Codony, A., Montes-Morán, M.A., Sánchez-Polo, M., Martín, M.J., Gonzalez-Olmos, R., 2014. Biogas upgrading: Optimal activated carbon properties for siloxane removal. Environ. Sci. Technol. 48. https://doi.org/10.1021/es501274a

10. Cabrera-Codony, A., Santos-Clotas, E., Ania, C.O., Martín, M.J., 2018. Competitive siloxane adsorption in multicomponent gas streams for biogas upgrading. Chem. Eng. J. 344. https://doi.org/10.1016/j.cej.2018.03.131

11. Cagnon, B., Py, X., Guillot, A., Stoeckli, F., Chambat, G., 2009. Contributions of hemicellulose, cellulose and lignin to the mass and the porous properties of chars and steam activated carbons from various lignocellulosic precursors. Bioresour. Technol. 100, 292-298. https://doi.org/10.1016/j.biortech.2008.06.009

12. Dastgheib, S.A., Karanfil, T., 2005. The effect of the physical and chemical characteristics of activated carbons on the adsorption energy and affinity coefficient of Dubinin equation. J. Colloid Interface Sci. 292, 312-321. https://doi.org/10.1016/j.jcis.2005.06.017

13. Demiral, H., Demiral, I., Tümsek, F., Karabacakoğlu, B., 2008. Pore structure of activated carbon prepared from hazelnut bagasse by chemical activation. Surf. Interface Anal. 40, 616-619. https://doi.org/10.1002/sia.2631

14. Dewil, R., Appels, L., Baeyens, J., 2006. Energy use of biogas hampered by the presence of siloxanes. Energy Convers. Manag. 47, 1711-1722. https://doi.org/10.1016/j.enconman.2005.10.016 
15. Ferrera-Lorenzo, N., Fuente, E., Suárez-Ruiz, I., Ruiz, B., 2014a. Sustainable activated carbons of macroalgae waste from the Agar-Agar industry. Prospects as adsorbent for gas storage at high pressures. Chem. Eng. J. 250, 128-136. https://doi.org/10.1016/j.cej.2014.03.119

16. Ferrera-Lorenzo, N., Fuente, E., Suárez-Ruiz, I., Ruiz, B., 2014b. KOH activated carbon from conventional and microwave heating system of a macroalgae waste from the Agar-Agar industry. Fuel Process. Technol. 121, 25-31. https://doi.org/10.1016/j.fuproc.2013.12.017

17. Gil, R.R., Girón, R.P., Lozano, M.S., Ruiz, B., Fuente, E., 2012. Pyrolysis of biocollagenic wastes of vegetable tanning. Optimization and kinetic study. J. Anal. Appl. Pyrolysis 98, 129-136. https://doi.org/10.1016/J.JAAP.2012.08.010

18. Gil, R.R., Ruiz, B., Lozano, M.S., Martín, M.J., Fuente, E., 2014. VOCs removal by adsorption onto activated carbons from biocollagenic wastes of vegetable tanning. Chem. Eng. J. 245, 80-88. https://doi.org/10.1016/j.cej.2014.02.012

19. Gimbert, F., Morin-Crini, N., Renault, F., Badot, P.M., Crini, G., 2008. Adsorption isotherm models for dye removal by cationized starch-based material in a single component system: Error analysis. J. Hazard. Mater. 157, 34-46. https://doi.org/10.1016/j.jhazmat.2007.12.072

20. Harry Marsh, F.R.-R., 2006. Activated Carbon, 1st ed, Elsevier Science and Technology Books. Elsevier. https://doi.org/10.1016/B978-0-08-044463-5.X5013-4

21. Ioannidou, O., Zabaniotou, A., 2007. Agricultural residues as precursors for activated carbon production-A review. Renew. Sustain. Energy Rev. 11, 1966-2005. https://doi.org/10.1016/j.rser.2006.03.013

22. Jiang, T., Zhong, W., Jafari, T., Du, S., He, J., Fu, Y.J., Singh, P., Suib, S.L., 
2016. Siloxane D4 adsorption by mesoporous aluminosilicates. Chem. Eng. J. 289, 356364. https://doi.org/10.1016/j.cej.2015.12.094

23. Kailappan, R., Gothandapani, L., Viswanathan, R., 2000. Production of activated carbon from prosopis (Prosopis juliflora). Bioresour. Technol. 75, 241-243. https://doi.org/10.1016/S0960-8524(00)00056-0

24. Li, W., Yang, K., Peng, J., Zhang, L., Guo, S., Xia, H., 2008. Effects of carbonization temperatures on characteristics of porosity in coconut shell chars and activated carbons derived from carbonized coconut shell chars. Ind. Crops Prod. 28, 190-198. https://doi.org/10.1016/j.indcrop.2008.02.012

25. Lillo-Ródenas, M.A., Cazorla-Amorós, D., Linares-Solano, A., 2005. Behaviour of activated carbons with different pore size distributions and surface oxygen groups for benzene and toluene adsorption at low concentrations. Carbon N. Y. 43, 1758-1767. https://doi.org/10.1016/j.carbon.2005.02.023

26. Liu, J., Hu, C., Huang, Q., 2018. Adsorption of $\mathrm{Cu} 2+, \mathrm{Pb} 2+$, and $\mathrm{Cd} 2+$ onto oiltea shell from water. Bioresour. Technol. 271, 487-491. https://doi.org/10.1016/j.biortech.2018.09.040

27. Lua, A.C., Yang, T., 2005. Characteristics of activated carbon prepared from pistachio-nut shell by zinc chloride activation under nitrogen and vacuum conditions. J. Colloid Interface Sci. 290, 505-513. https://doi.org/10.1016/j.jcis.2005.04.063

28. Matsui, T., Imamura, S., 2010. Removal of siloxane from digestion gas of $\begin{array}{lllll}\text { sewage } & \text { sludge. } & \text { Bioresour. } & \text { Technol. } & \text { S29-S32. }\end{array}$ https://doi.org/10.1016/j.biortech.2009.05.037

29. Mui, E.L.K., Cheung, W.H., Valix, M., McKay, G., 2010. Mesoporous activated carbon from waste tyre rubber for dye removal from effluents. Microporous 
Mesoporous Mater. 130, 287-294. https://doi.org/10.1016/j.micromeso.2009.11.022

30. Nam, S., Namkoong, W., Kang, J.H., Park, J.K., Lee, N., 2013. Adsorption characteristics of siloxanes in landfill gas by the adsorption equilibrium test. Waste Manag. 33, 2091-2098. https://doi.org/10.1016/j.wasman.2013.03.024

31. Neyens, E., Baeyens, J., Dewil, R., De Heyder, B., 2004. Advanced sludge treatment affects extracellular polymeric substances to improve activated sludge $\begin{array}{lllll}\text { dewatering. } & \text { J. } & \text { Hazard. } & \text { Mater. } & \text { 83-92. }\end{array}$ https://doi.org/10.1016/j.jhazmat.2003.11.014

32. Olivier, J.P., Conklin, W.B., Szombathely, M. v., 1994. Determination of Pore Size Distribution from Density Functional Theory: A Comparison of Nitrogen and Argon Results. Stud. Surf. Sci. Catal. 87, 81-89. https://doi.org/10.1016/S01672991(08)63067-0

33. Oshita, K., Ishihara, Y., Takaoka, M., Takeda, N., Matsumoto, T., Morisawa, S., Kitayama, A., 2010. Behaviour and adsorptive removal of siloxanes in sewage sludge biogas. Water Sci. Technol. 61, 2003-2012. https://doi.org/10.2166/wst.2010.101

34. Qian, Q., Gong, C., Zhang, Z., Yuan, G., 2015. Removal of VOCs by activated carbon microspheres derived from polymer: a comparative study. Adsorption 21, 333341. https://doi.org/10.1007/s10450-015-9673-9

35. Rodríguez-Mirasol, J., Bedia, J., Cordero, T., Rodríguez, J., 2005. Influence of water vapor on the adsorption of VOCs on lignin-based activated carbons. Sep. Sci. Technol. 40, 3113-3135. https://doi.org/10.1080/01496390500385277

36. Ros, A., Lillo-Ródenas, M.A., Fuente, E., Montes-Morán, M.A., Martín, M.J., Linares-Solano, A., 2006. High surface area materials prepared from sewage sludge$\begin{array}{llll}\text { based } & \text { precursors. } & \text { Chemosphere } & \text { 65, }\end{array}$ 
https://doi.org/10.1016/j.chemosphere.2006.02.017

37. Ruiz, B., Ferrera-Lorenzo, N., Fuente, E., 2017. Valorisation of lignocellulosic wastes from the candied chestnut industry. Sustainable activated carbons for environmental applications. J. Environ. Chem. Eng. 5, 1504-1515. https://doi.org/10.1016/j.jece.2017.02.028

38. Ruiz, B., Ruisánchez, E., Gil, R.R., Ferrera-Lorenzo, N., Lozano, M.S., Fuente, E., 2015. Sustainable porous carbons from lignocellulosic wastes obtained from the extraction of tannins. Microporous Mesoporous Mater. 209, 23-29. https://doi.org/10.1016/j.micromeso.2014.09.004

39. Spahis, N., Addoun, A., Mahmoudi, H., Ghaffour, N., 2008. Purification of water by activated carbon prepared from olive stones. Desalination 222, 519-527. https://doi.org/10.1016/j.desal.2007.02.065

40. Stoeckli, F., Ballerini, L., 1991. Evolution of microporosity during activation of carbon. Fuel 70, 557-559. https://doi.org/10.1016/0016-2361(91)90036-A

41. Suhas, Gupta, V.K., Carrott, P.J.M., Singh, R., Chaudhary, M., Kushwaha, S., 2016. Cellulose: A review as natural, modified and activated carbon adsorbent. Bioresour. Technol. 216, 1066-1076. https://doi.org/10.1016/j.biortech.2016.05.106 42. Tan, X. fei, Liu, S. bo, Liu, Y. guo, Gu, Y. ling, Zeng, G. ming, Hu, X. jiang, Wang, X., Liu, S. heng, Jiang, L. hua, 2017. Biochar as potential sustainable precursors for activated carbon production: Multiple applications in environmental protection and $\begin{array}{llll}\text { energy } & \text { storage. } & \text { Bioresour. } & \text { Technol. }\end{array}$ https://doi.org/10.1016/j.biortech.2016.12.083

43. Thommes, M., Kaneko, K., Neimark, A. V., Olivier, J.P., Rodriguez-Reinoso, F., Rouquerol, J., Sing, K.S.W., 2015. Physisorption of gases, with special reference to 
the evaluation of surface area and pore size distribution (IUPAC Technical Report). Pure Appl. Chem. 87, 1051-1069. https://doi.org/10.1515/pac-2014-1117

44. Wang, B., Li, C., Liang, H., 2013. Bioleaching of heavy metal from woody biochar using Acidithiobacillus ferrooxidans and activation for adsorption. Bioresour. Technol. 146, 803-806. https://doi.org/10.1016/j.biortech.2013.08.020

45. Yahya, M.A., Al-Qodah, Z., Ngah, C.W.Z., 2015. Agricultural bio-waste materials as potential sustainable precursors used for activated carbon production: A review. Renew. Sustain. Energy Rev. 46, 218-235. https://doi.org/10.1016/j.rser.2015.02.051

46. Yang, X., Yi, H., Tang, X., Zhao, S., Yang, Z., Ma, Y., Feng, T., Cui, X., 2018. Behaviors and kinetics of toluene adsorption - desorption on activated carbons with varying pore structure. J. Environ. Sci. (China) 67, 104-114. https://doi.org/10.1016/j.jes.2017.06.032

47. Zhang, X., Fu, W., Yin, Y., Chen, Z., Qiu, R., Simonnot, M.O., Wang, X., 2018. Adsorption-reduction removal of $\mathrm{Cr}(\mathrm{VI})$ by tobacco petiole pyrolytic biochar: Batch experiment, kinetic and mechanism studies. Bioresour. Technol. 268, 149-157. https://doi.org/10.1016/j.biortech.2018.07.125

48. Zhang, X., Zhang, S., Yang, H., Feng, Y., Chen, Y., Wang, X., Chen, H., 2014. Nitrogen enriched biochar modified by high temperature $\mathrm{CO} 2$-ammonia treatment: Characterization and adsorption of CO2. Chem. Eng. J. 257, 20-27. https://doi.org/10.1016/j.cej.2014.07.024 


\section{Figure captions}

Fig. $1 \mathrm{~N}_{2}$ adsorption/desorption at $77 \mathrm{~K}(\mathrm{~A})$ and $\mathrm{CO}_{2}$ adsorption isotherms at $273 \mathrm{~K}$ (B) for the experimental (green dashed lines) and commercial carbons (black/grey solid lines)

Fig. 2 Gas uptake obtained at different equilibrium concentration $\left(\mathrm{C}_{\mathrm{e}}\right)$ of (A) D4, (B) L2, (C) limonene and (D) toluene in static adsorption tests at $25^{\circ} \mathrm{C}$ and DA fitting (lines).

Fig. 3 Relationships between total pore volume $\left(\mathrm{V}_{\text {TОT }}\right)$ and micropore volume $\left(\mathrm{V}_{\mathrm{mi}}\right)$ with adsorption capacity of (A-B) L2, (C-D) D4, (E-F) toluene and (G-H) limonene (calculated on a dry basis by DA adjust). Green circles represent experimental ACs and black squares commercial ACs.

Fig. 4 Percentage of A) L2 and B) D4 recovered or transformed to other siloxanes and $\alpha-\omega$ silanediols from THF extraction of spend samples. Non-extracted refers to the amount of siloxane adsorbed and not detected on the THF extracts. 
Table 1

Activation conditions of the lignocellulosic waste activated carbons and commercial samples.

\begin{tabular}{llllll}
\hline Sample & Precursor & $\begin{array}{l}\text { Activating } \\
\text { agent }\end{array}$ & $\begin{array}{l}\text { Activating } \\
\text { agent/precursor } \\
\text { weight ratio }\end{array}$ & $\begin{array}{l}\text { Activation } \\
\text { temperature } \\
{\left[{ }^{\circ} \mathrm{C}\right]}\end{array}$ & $\begin{array}{l}\mathrm{N}_{2} \\
\text { rate } \\
{\left[\mathrm{cm}^{3} \mathrm{~min}^{-1}\right]}\end{array}$ \\
\hline Experimental & & & & \\
AC1 & Lignocellulosic waste & $\mathrm{K}_{2} \mathrm{CO}_{3}$ & $1 / 1$ & 850 & 150 \\
$\mathrm{AC} 2$ & Lignocellulosic waste & $\mathrm{K}_{2} \mathrm{CO}_{3}$ & $0.5 / 1$ & 900 & 150 \\
$\mathrm{AC} 3$ & Pyrolyzed lignocellulosic waste & $\mathrm{KOH}$ & $0.5 / 1$ & 900 & 150 \\
$\mathrm{AC} 4$ & Pyrolyzed lignocellulosic waste & $\mathrm{KOH}$ & $1 / 1$ & 900 & 150 \\
\hline Commercial & & & & \\
AC5 & Lignocellulosic material & $\mathrm{H}_{3} \mathrm{PO}_{4}$ & n.a. & n.a. & n.a. \\
AC6 & Anthracite & Steam & n.a. & n.a. & n.a. \\
AC7 & Coal & Steam & n.a. & n.a. & n.a. \\
\hline
\end{tabular}

n.a. non-available 
Table 2

Target compounds properties

\begin{tabular}{lllll}
\hline Compound & $\begin{array}{l}\text { Molecular } \\
\text { formula }\end{array}$ & $\begin{array}{l}\text { Molecular weight } \\
{\left[\mathrm{g} \mathrm{mol}^{-1}\right]}\end{array}$ & $\begin{array}{l}\text { Boiling point } \\
{\left[{ }^{\circ} \mathrm{C}\right]}\end{array}$ & $\begin{array}{l}\text { Critical diameter } \\
{[\mathrm{mm}]}\end{array}$ \\
\hline $\mathrm{L} 2$ & $\mathrm{C}_{6} \mathrm{H}_{18} \mathrm{OSi}_{2}$ & 162.4 & 100 & 0.73 \\
$\mathrm{D} 4$ & $\mathrm{C}_{8} \mathrm{H}_{24} \mathrm{O}_{4} \mathrm{Si}_{4}$ & 296.6 & 175 & 1.08 \\
Toluene & $\mathrm{C}_{7} \mathrm{H}_{8}$ & 92.1 & 111 & 0.67 \\
Limonene & $\mathrm{C}_{10} \mathrm{H}_{16}$ & 136.2 & 176 & 0.68 \\
\hline
\end{tabular}


Table 3.

Proximate and ultimate analysis of the activated carbons

\begin{tabular}{|c|c|c|c|c|c|c|c|}
\hline \multirow{2}{*}{ Sample } & \multirow[b]{2}{*}{ Humidity $^{\mathrm{a}}$} & \multicolumn{6}{|c|}{ Mass fraction (\%), dry basis } \\
\hline & & Ash & $\mathrm{C}$ & $\mathrm{H}$ & $\mathrm{N}$ & $\mathrm{S}$ & $\mathrm{O}^{\mathrm{b}}$ \\
\hline \multicolumn{8}{|c|}{ Experimental } \\
\hline $\mathrm{AC} 1$ & 10.1 & 0.21 & 95.76 & 0.50 & 1.48 & 0.11 & 1.94 \\
\hline $\mathrm{AC} 2$ & 6.0 & 0.40 & 95.15 & 0.42 & 1.39 & 0.13 & 2.51 \\
\hline $\mathrm{AC} 3$ & 15.9 & 1.29 & 94.60 & 0.37 & 1.52 & 0.08 & 2.14 \\
\hline $\mathrm{AC} 4$ & 11.7 & 1.05 & 95.08 & 0.30 & 1.29 & 0.10 & 2.18 \\
\hline \multicolumn{8}{|c|}{ Commercial } \\
\hline AC5 & 18.9 & 9.65 & 80.15 & 2.31 & 0.51 & 0.01 & 7.37 \\
\hline AC6 & 6.9 & 7.50 & 89.50 & 0.65 & 0.63 & 0.40 & 1.32 \\
\hline $\mathrm{AC7}$ & 5.2 & 9.29 & 88.06 & 0.55 & 0.60 & 0.44 & 1.06 \\
\hline
\end{tabular}

${ }^{\mathrm{a}}$ Determined as-received

${ }^{\mathrm{b}}$ Determined by difference 
Table 4

Textural parameters of the materials

\begin{tabular}{lllllllllll}
\hline \multicolumn{1}{c}{$\mathrm{N}_{2}$ adsorption at 77K } & \multicolumn{5}{c}{$\mathrm{CO}_{2}$ adsorption at 273K } \\
\hline Sample & $\begin{array}{l}\rho_{\mathrm{He}} \\
{\left[\mathrm{g} \mathrm{cm}^{-3}\right]}\end{array}$ & $\begin{array}{l}\mathrm{S}_{\mathrm{BET}} \\
{\left[\mathrm{m}^{2} \mathrm{~g}^{-1}\right]}\end{array}$ & $\begin{array}{l}\mathrm{V}_{\mathrm{TOT}} \\
{\left[\mathrm{cm}^{3} \mathrm{~g}^{-1}\right]}\end{array}$ & $\begin{array}{l}{ }^{\mathrm{a}} \mathrm{V}_{\text {umi }} \\
{\left[\mathrm{cm}^{3} \mathrm{~g}^{-1}\right]}\end{array}$ & $\begin{array}{l}{ }^{\mathrm{b}} \mathrm{V}_{\mathrm{mmi}} \\
{\left[\mathrm{cm}^{3} \mathrm{~g}^{-1}\right]}\end{array}$ & $\begin{array}{l}{ }^{\mathrm{c}} \mathrm{V}_{\mathrm{me}} \\
{\left[\mathrm{cm}^{3} \mathrm{~g}^{-1}\right]}\end{array}$ & $\begin{array}{l}\mathrm{W}_{0} \\
{\left[\mathrm{~cm}^{3} \mathrm{~g}^{-1}\right]}\end{array}$ & $\begin{array}{l}\mathrm{S}_{\mathrm{DR}} \\
{\left[\mathrm{m}^{2} \mathrm{~g}^{-1}\right]}\end{array}$ & $\begin{array}{l}\mathrm{E}_{0} \\
{\left[\mathrm{KJ} \mathrm{mol}^{-1}\right]}\end{array}$ & $\begin{array}{l}\mathrm{L} \\
{[\mathrm{nm}]}\end{array}$ \\
\hline $\mathrm{AC} 1$ & 2.19 & 1512 & 0.63 & 0.26 & 0.22 & 0.02 & 0.42 & 1123 & 23.00 & 0.90 \\
$\mathrm{AC} 2$ & 2.12 & 1668 & 0.70 & 0.25 & 0.28 & 0.03 & 0.63 & 1692 & 23.78 & 0.83 \\
$\mathrm{AC} 3$ & 2.05 & 1025 & 0.40 & 0.22 & 0.11 & 0.00 & 0.45 & 1215 & 26.48 & 0.70 \\
$\mathrm{AC} 4$ & 2.13 & 1419 & 0.57 & 0.24 & 0.21 & 0.01 & 0.73 & 1899 & 25.13 & 0.72 \\
$\mathrm{AC5}$ & 1.74 & 1659 & 0.86 & 0.09 & 0.36 & 0.28 & 0.26 & 683 & 24.61 & 0.82 \\
$\mathrm{AC6}$ & 2.15 & 862 & 0.39 & 0.10 & 0.17 & 0.03 & 0.21 & 560 & 26.90 & 0.70 \\
$\mathrm{AC7}$ & 2.31 & 1281 & 0.63 & 0.10 & 0.25 & 0.17 & 0.20 & 527 & 25.49 & 0.77 \\
\hline
\end{tabular}

${ }^{\mathrm{a}} \mathrm{V}_{\text {umi }}$ : ultramicropore volume (pore width $<0.7 \mathrm{~nm}$ )

${ }^{\mathrm{b}} \mathrm{V}_{\mathrm{mmi}}$ : medium-micropore volume (pore width $0.7-2 \mathrm{~nm}$ )

${ }^{\mathrm{c}} \mathrm{V}_{\mathrm{me}}$ : mesopore volume (pore width 2-50 nm) 
Table 5.

Adsorption capacities $(\mathrm{x} / \mathrm{M})$, values of $\mathrm{n}$ and $\beta$ determined by Dubinin-Astakhov equation and $\mathrm{r}^{2}$ obtained from the model fitting.

\begin{tabular}{|c|c|c|c|c|c|c|c|c|}
\hline Pollutant & Parameter & $\mathrm{AC} 1$ & $\mathrm{AC2}$ & $\mathrm{AC} 3$ & $\mathrm{AC} 4$ & AC5 & AC6 & $\mathrm{AC7}$ \\
\hline \multirow[t]{4}{*}{$\mathrm{L} 2$} & $\mathrm{x} / \mathrm{M}\left[\mathrm{mg} \mathrm{g}^{-1}\right]$ & 359 & 438 & 220 & 321 & 394 & 255 & 314 \\
\hline & $\mathrm{n}$ & 3.80 & 3.10 & 3.06 & 3.26 & 3.50 & 2.38 & 2.73 \\
\hline & $\beta$ & 1,57 & 1.32 & 1.69 & 0.97 & 1.44 & 1.50 & 1.57 \\
\hline & $\mathrm{r}^{2}$ & 0.982 & 0.977 & 0.976 & 0.984 & 0.976 & 0.919 & 0.975 \\
\hline \multirow[t]{4}{*}{ D4 } & $\mathrm{x} / \mathrm{M}\left[\mathrm{mg} \mathrm{g}^{-1}\right]$ & 436 & 512 & 185 & 356 & 577 & 233 & 398 \\
\hline & $\mathrm{n}$ & 2.93 & 3.26 & 2.94 & 2.36 & 2.44 & 2.08 & 5.71 \\
\hline & $\beta$ & 1.84 & 1.75 & 1.11 & 1.92 & 2.15 & 2.57 & 1.50 \\
\hline & $r^{2}$ & 0.996 & 0.899 & 0.997 & 0.941 & 0.994 & 0.893 & 0.962 \\
\hline \multirow[t]{4}{*}{ Toluene } & $\mathrm{x} / \mathrm{M}\left[\mathrm{mg} \mathrm{g}^{-1}\right]$ & 374 & 417 & 255 & 318 & 343 & 192 & 268 \\
\hline & $\mathrm{n}$ & 3.01 & 3.41 & 4.59 & 4.79 & 2.31 & 2.96 & 2.13 \\
\hline & $\beta$ & 1.00 & 1.00 & 1.00 & 1.00 & 1.00 & 1.00 & 1.00 \\
\hline & $r^{2}$ & 0.970 & 0.975 & 0.996 & 0.990 & 0.992 & 0.957 & 0.983 \\
\hline \multirow[t]{4}{*}{ Limonene } & $\mathrm{x} / \mathrm{M}\left[\mathrm{mg} \mathrm{g}^{-1}\right]$ & 427 & 446 & 282 & 408 & 452 & 275 & 354 \\
\hline & $\mathrm{n}$ & 2.53 & 3.11 & 3.93 & 2.13 & 2.04 & 2.33 & 3.51 \\
\hline & $\beta$ & 1.61 & 1.05 & 1.01 & 1.57 & 1.41 & 1.04 & 1.13 \\
\hline & $r^{2}$ & 0.988 & 0.997 & 0.943 & 0.989 & 0.988 & 0.936 & 0.967 \\
\hline
\end{tabular}

$\beta$ - Affinity coefficient (calculated from the adsorption energy in the DA equation $E=\beta E_{0}$ ) where toluene is taken as a reference compound assuming $\beta_{\text {TOLUENE }}=1$. 

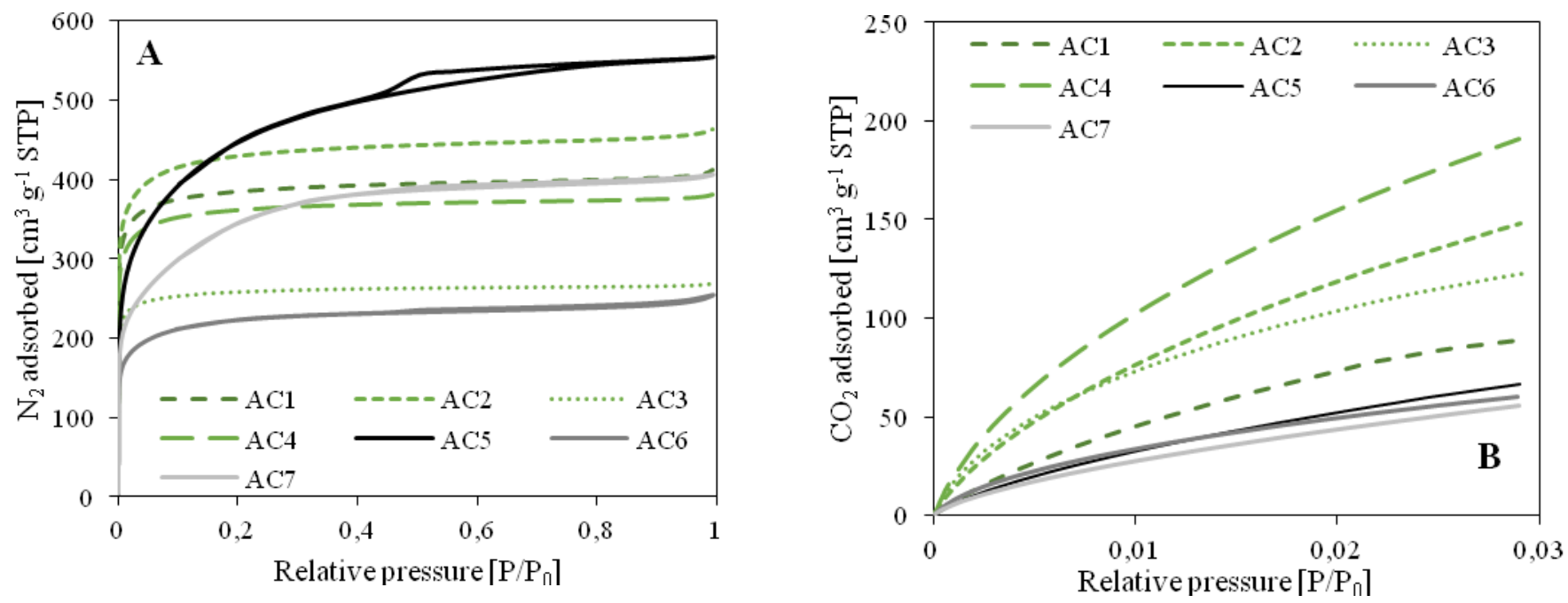

Fig. $1 \mathrm{~N}_{2}$ adsorption/desorption at $77 \mathrm{~K}(\mathrm{~A})$ and $\mathrm{CO}_{2}$ adsorption isotherms at $273 \mathrm{~K}$ (B) for the experimental (green dashed lines) and commercial carbons (black/grey solid lines) 

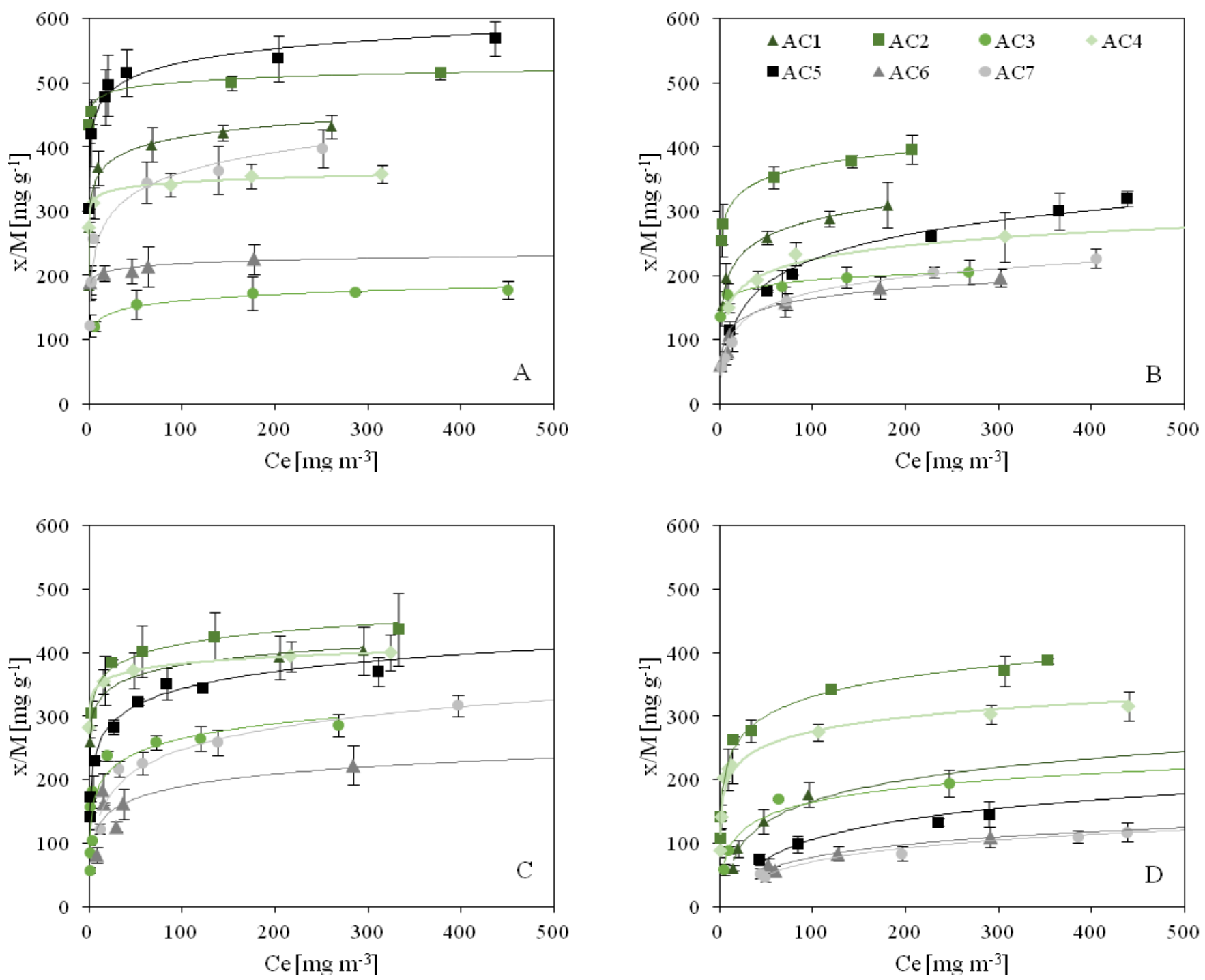

Fig. 2 Gas uptake obtained at different equilibrium concentration (Ce) of (A) D4, (B) L2, (C) limonene and (D) toluene in static adsorption tests at $25^{\circ} \mathrm{C}$ and DA fitting (lines). 

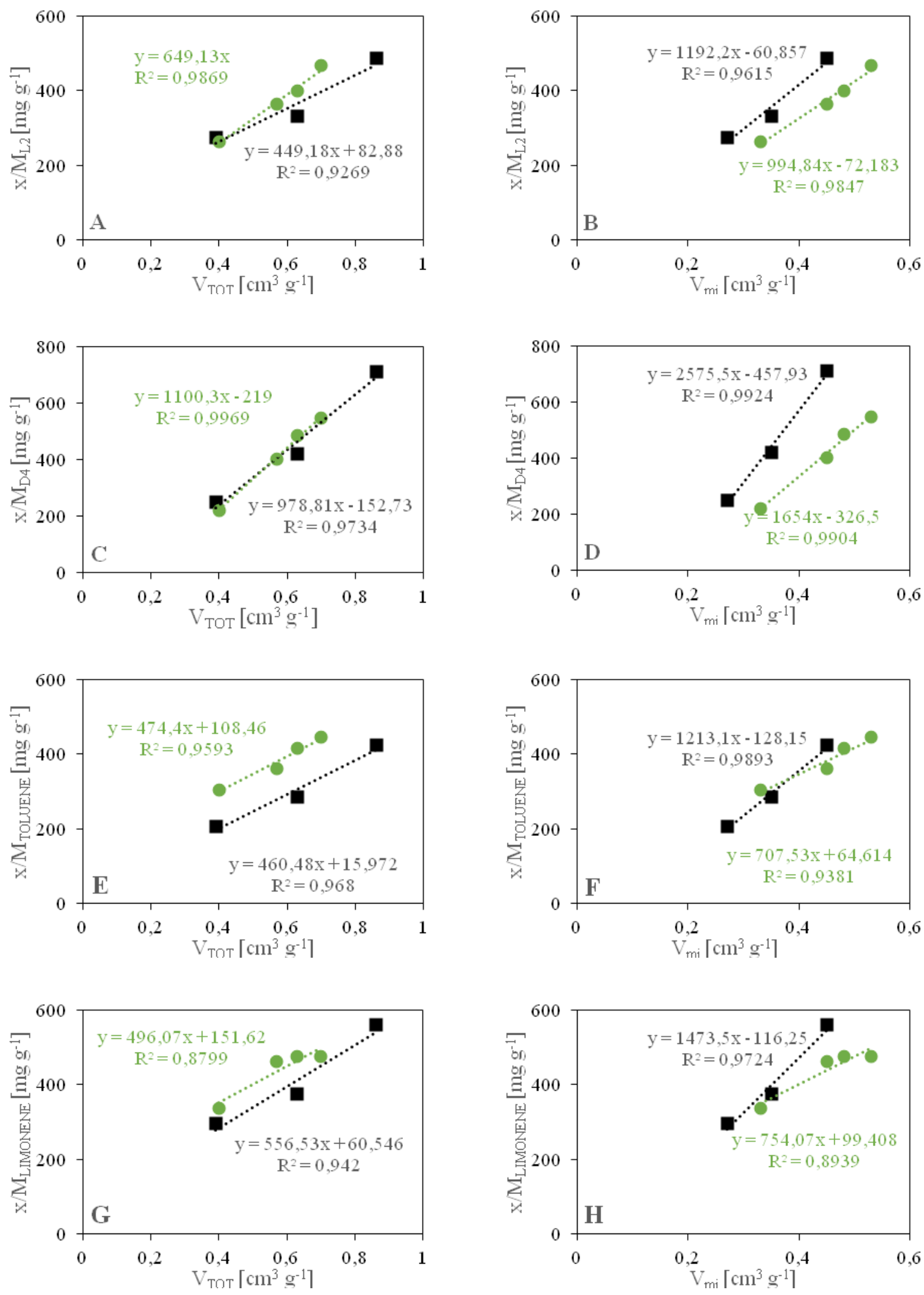

Fig. 3 Relationships between total pore volume $\left(\mathrm{V}_{\text {TOT }}\right)$ and micropore volume $\left(\mathrm{V}_{\mathrm{mi}}\right)$ with adsorption capacity of (A-B) L2, (C-D) D4, (E-F) toluene and (G-H) limonene (calculated on a dry basis by DA adjust). Green circles 
represent experimental ACs and black squares commercial ACs.

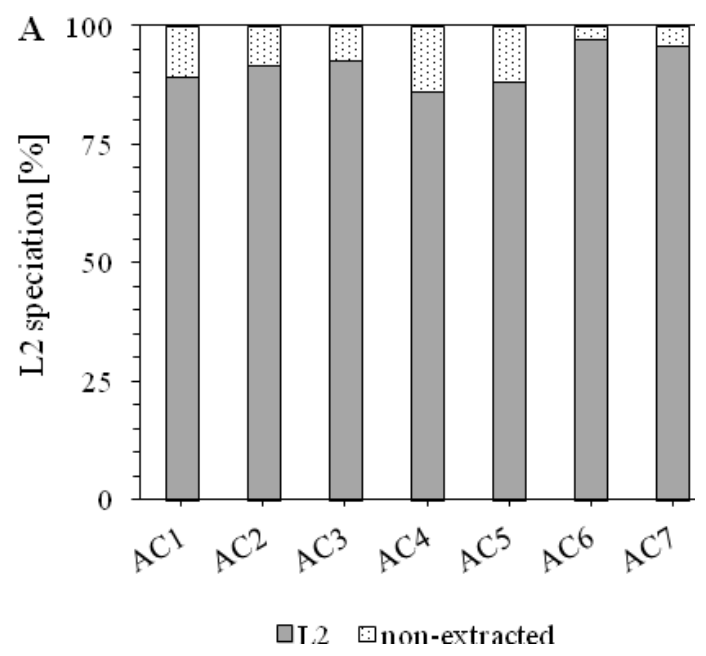

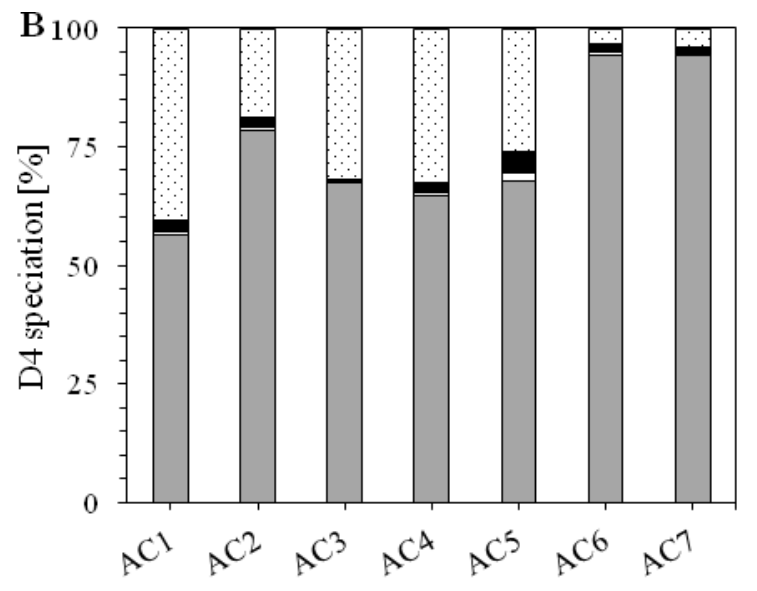

$\square$ D4 $\square(t-()$-silanediols $\square$ other siloxanes $\square$ non-extracted

Fig. 4 Percentage of A) L2 and B) D4 recovered or transformed to other siloxanes and $\alpha$ - $\omega$-silanediols from THF extraction of spend samples. Non-extracted refers to the amount of siloxane adsorbed and not detected on the THF extracts. 


\section{Supplementary information for:}

Sewage biogas efficient purification by means of lignocellulosic waste-

\section{based activated carbons}

Eric Santos-Clotas ${ }^{1}$, Alba Cabrera-Codony ${ }^{1}$, B. Ruiz ${ }^{2}$, E. Fuente ${ }^{2}$, Maria J Martín ${ }^{1 *}$

${ }^{1}$ LEQUIA. Institute of Environment. University of Girona, Campus Montilivi, Maria Aurèlia Capmany 69, E-17003 Girona. Catalonia. Spain

${ }^{2}$ Biocarbon and Sustainability Group (B\&S); Instituto Nacional del Carbon (INCAR), CSIC. C/ Francisco Pintado Fe, 26, 33011 Oviedo, Spain

"Corresponding author: E-mail address: maria.martin@udg.edu, Tel: +34972419261
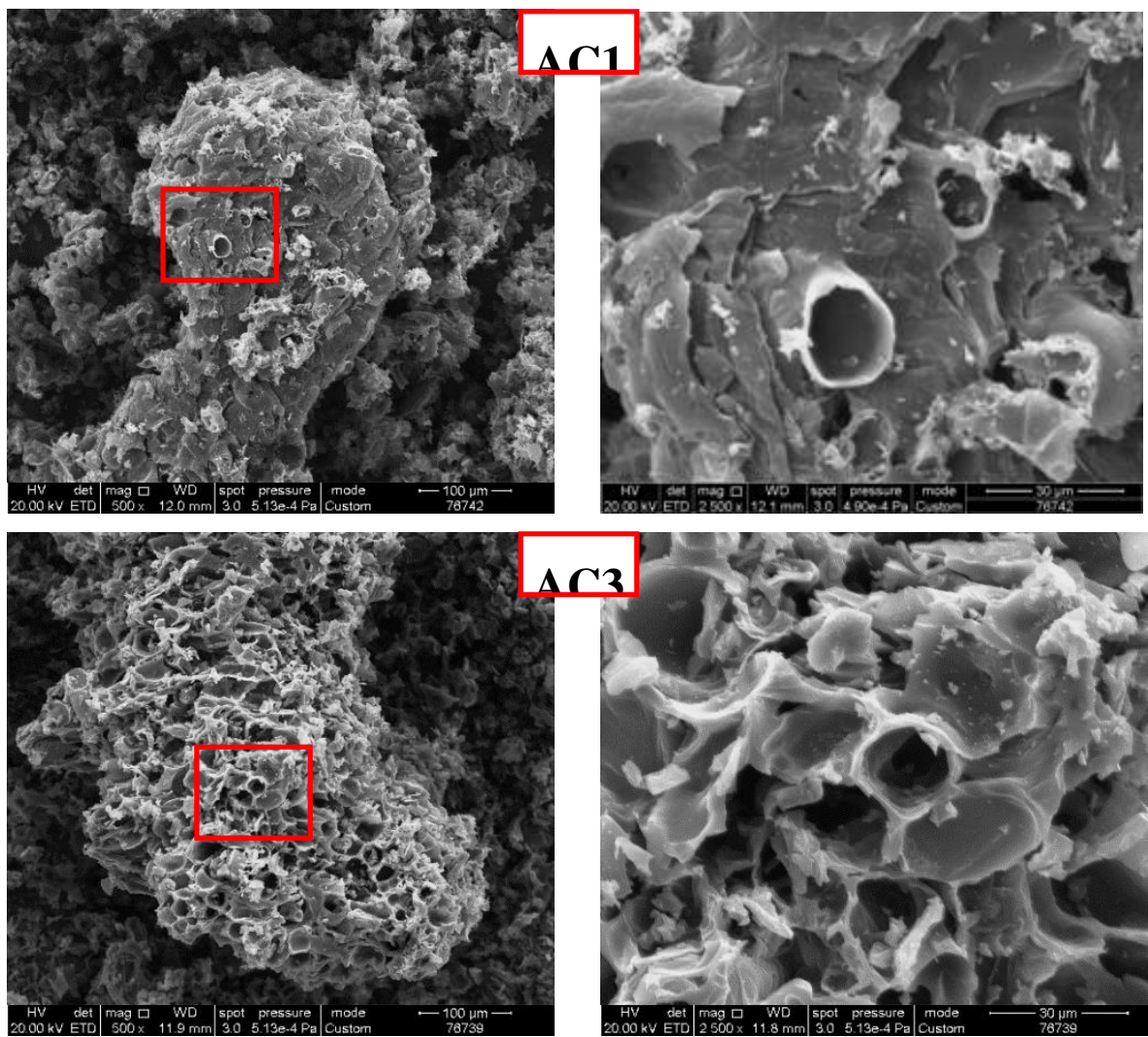

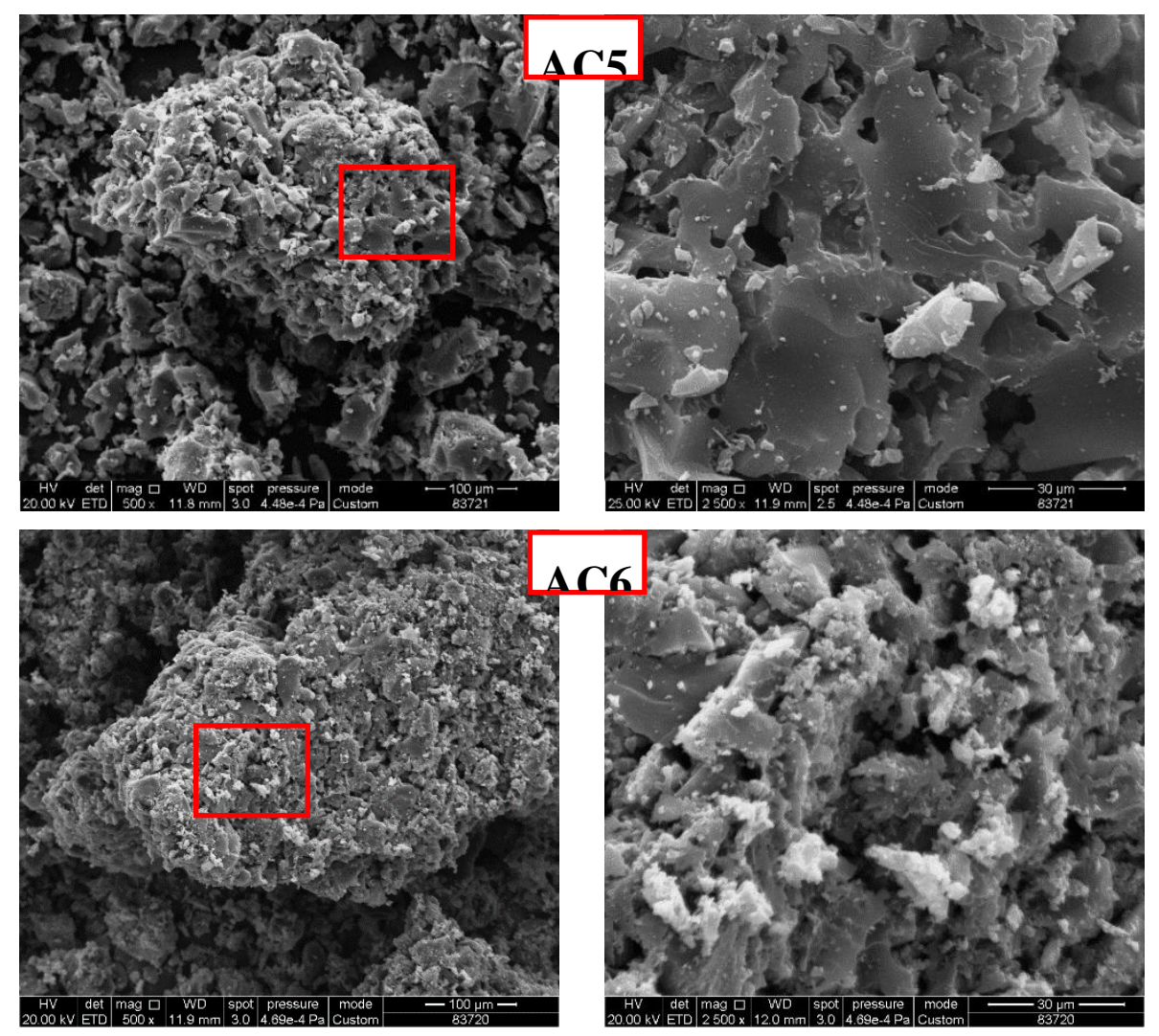

Fig. S1 SEM pictures of two experimental (AC1 and AC3) and two commercial ACs (AC5 and AC6) at magnifications x500 (left side) and x2500 (right side). 


\section{Table S1}

Results of the static adsorption tests performed including equilibrum concentration (Ce), adsorption capacity mean value (x/M), standard deviation (SD) amd coefficient of variation (CV) of the adsorption capacities obtained in sets of three experiments for AC1.

\begin{tabular}{|c|c|c|c|c|c|c|c|c|c|c|c|c|c|c|c|}
\hline \multicolumn{4}{|l|}{ D4 } & \multicolumn{4}{|l|}{ L2 } & \multicolumn{4}{|l|}{ Toluene } & \multicolumn{4}{|c|}{ Limonene } \\
\hline $\begin{array}{l}\mathrm{Ce} \\
{\left[\mathrm{mg} \mathrm{m}^{-3}\right]}\end{array}$ & $\begin{array}{l}\mathrm{x} / \mathrm{M} \\
{\left[\mathrm{mg} \mathrm{g}^{-1}\right]}\end{array}$ & $\begin{array}{l}\mathrm{SD} \\
{\left[\mathrm{mg} \mathrm{g}^{-1}\right]}\end{array}$ & $\begin{array}{l}\mathrm{CV} \\
{[\%]}\end{array}$ & $\begin{array}{l}\mathrm{Ce} \\
{\left[\mathrm{mg} \mathrm{m}^{-3}\right]}\end{array}$ & $\begin{array}{l}\mathrm{x} / \mathrm{M} \\
{\left[\mathrm{mg} \mathrm{g}^{-1}\right]}\end{array}$ & $\begin{array}{l}\text { SD } \\
{\left[\mathrm{mg} \mathrm{g}^{-1}\right]}\end{array}$ & $\begin{array}{l}\mathrm{CV} \\
{[\%]} \\
\end{array}$ & $\begin{array}{l}\mathrm{Ce} \\
{\left[\mathrm{mg} \mathrm{m}^{-3}\right]}\end{array}$ & $\begin{array}{l}\mathrm{x} / \mathrm{M} \\
{\left[\mathrm{mg} \mathrm{g}^{-1}\right]}\end{array}$ & $\begin{array}{l}\mathrm{SD} \\
{\left[\mathrm{mg} \mathrm{g}^{-1}\right]}\end{array}$ & $\begin{array}{l}\mathrm{CV} \\
{[\%]}\end{array}$ & \begin{tabular}{|l}
$\mathrm{Ce}$ \\
{$\left[\mathrm{mg} \mathrm{m}^{-3}\right]$}
\end{tabular} & $\begin{array}{l}\mathrm{x} / \mathrm{M} \\
{\left[\mathrm{mg} \mathrm{g}^{-1}\right]}\end{array}$ & $\begin{array}{l}\text { SD } \\
{\left[\mathrm{mg} \mathrm{g}^{-1}\right]}\end{array}$ & $\begin{array}{l}\mathrm{CV} \\
{[\%]}\end{array}$ \\
\hline 9.6 & 367.7 & 27.0 & 7.3 & 3.6 & 153.6 & 3.2 & 2.1 & 14.9 & 60.7 & 4.7 & 7.7 & 1.2 & 259.1 & 20.1 & 7.7 \\
\hline 67.5 & 403.7 & 27.0 & 6.7 & 6.7 & 197.2 & 21.7 & 11.0 & 20.0 & 91.3 & 13.6 & 14.9 & 17.1 & 356.3 & 39.2 & 11.0 \\
\hline 143.9 & 421.7 & 12.1 & 2.9 & 51.3 & 258.3 & 10.5 & 4.0 & 47.1 & 134.1 & 19.7 & 14.7 & 204.7 & 392.5 & 35.2 & 9.0 \\
\hline \multirow[t]{2}{*}{260.4} & 432.2 & 18.7 & 4.3 & 118.1 & 288.1 & 12.1 & 4.2 & 95.9 & 176.4 & 19.9 & 11.3 & 294.7 & 403.7 & 38.1 & 9.4 \\
\hline & & & & 180.7 & 310.3 & 34.9 & 11.3 & 521.4 & 246.3 & 55.7 & 22.6 & & & & \\
\hline
\end{tabular}

\section{Table S2}

Results of the static adsorption tests performed including equilibrum concentration (Ce), adsorption capacity mean value (x/M), standard deviation (SD) amd coefficient of variation (CV) of the adsorption capacities obtained in sets of three experiments for AC2.

\begin{tabular}{|c|c|c|c|c|c|c|c|c|c|c|c|c|c|c|c|}
\hline \multicolumn{4}{|l|}{ D4 } & \multicolumn{4}{|l|}{ L2 } & \multicolumn{4}{|l|}{ Toluene } & \multicolumn{4}{|c|}{ Limonene } \\
\hline $\begin{array}{l}\mathrm{Ce} \\
{\left[\mathrm{mg} \mathrm{m}^{-3}\right]}\end{array}$ & $\begin{array}{l}\mathrm{x} / \mathrm{M} \\
{\left[\mathrm{mg} \mathrm{g}^{-1}\right]}\end{array}$ & $\begin{array}{l}\mathrm{SD} \\
{\left[\mathrm{mg} \mathrm{g}^{-1}\right]}\end{array}$ & $\begin{array}{l}\mathrm{CV} \\
{[\%]}\end{array}$ & $\begin{array}{l}\mathrm{Ce} \\
{\left[\mathrm{mg} \mathrm{m}^{-3}\right]}\end{array}$ & $\begin{array}{l}\mathrm{x} / \mathrm{M} \\
{\left[\mathrm{mg} \mathrm{g}^{-1}\right]}\end{array}$ & $\begin{array}{l}\mathrm{SD} \\
{\left[\mathrm{mg} \mathrm{g}^{-1}\right]}\end{array}$ & $\begin{array}{l}\mathrm{CV} \\
{[\%]}\end{array}$ & $\begin{array}{l}\mathrm{Ce} \\
{\left[\mathrm{mg} \mathrm{m}^{-3}\right]}\end{array}$ & $\begin{array}{l}\mathrm{x} / \mathrm{M} \\
{\left[\mathrm{mg} \mathrm{g}^{-1}\right]}\end{array}$ & $\begin{array}{l}\text { SD } \\
{\left[\mathrm{mg} \mathrm{g}^{-1}\right]}\end{array}$ & $\begin{array}{l}\mathrm{CV} \\
{[\%]}\end{array}$ & $\begin{array}{l}\mathrm{Ce} \\
{\left[\mathrm{mg} \mathrm{m}^{-3}\right]}\end{array}$ & $\begin{array}{l}\mathrm{x} / \mathrm{M} \\
{\left[\mathrm{mg} \mathrm{g}^{-1}\right]}\end{array}$ & $\begin{array}{l}\text { SD } \\
{\left[\mathrm{mg} \mathrm{g}^{-1}\right]}\end{array}$ & $\begin{array}{l}\mathrm{CV} \\
{[\%]}\end{array}$ \\
\hline 2.5 & 455.2 & 18.5 & 4.1 & 2.5 & 254.7 & 24.7 & 9.7 & 1.2 & 141.8 & 6.2 & 4.3 & 2.5 & 304.9 & 19.0 & 6.2 \\
\hline 153.2 & 500.0 & 11.0 & 2.2 & 58.4 & 352.7 & 17.5 & 5.0 & 14.5 & 262.1 & 5.8 & 2.2 & 24.3 & 385.0 & 4.7 & 1.2 \\
\hline 377.6 & 515.7 & 10.0 & 1.9 & 142.4 & 378.2 & 10.1 & 2.7 & 33.7 & 276.7 & 17.8 & 6.4 & 56.9 & 402.2 & 40.4 & 10.0 \\
\hline \multirow[t]{3}{*}{694.0} & 529.1 & 5.9 & 1.1 & 206.5 & 396.6 & 22.1 & 5.6 & 119.4 & 342.3 & 5.4 & 1.6 & 134.8 & 425.8 & 38.5 & 9.0 \\
\hline & & & & & & & & 306.2 & 371.4 & 24.5 & 6.6 & 332.2 & 436.6 & 56.5 & 12.9 \\
\hline & & & & & & & & 352.3 & 387.9 & 4.4 & 1.1 & & & & \\
\hline
\end{tabular}

\section{Table S3}

Results of the static adsorption tests performed including equilibrum concentration $(\mathrm{Ce})$, adsorption capacity mean value (x/M), standard deviation (SD) amd coefficient of variation (CV) of the adsorption capacities obtained in sets of three experiments for AC3.

\begin{tabular}{|c|c|c|c|c|c|c|c|c|c|c|c|c|c|c|c|}
\hline \multicolumn{4}{|l|}{ D4 } & \multicolumn{4}{|l|}{ L2 } & \multicolumn{4}{|l|}{ Toluene } & \multicolumn{4}{|c|}{ Limonene } \\
\hline $\begin{array}{l}\mathrm{Ce} \\
{\left[\mathrm{mg} \mathrm{m}^{-3}\right]}\end{array}$ & $\begin{array}{l}\mathrm{x} / \mathrm{M} \\
{\left[\mathrm{mg} \mathrm{g}^{-1}\right]}\end{array}$ & $\begin{array}{l}\text { SD } \\
{\left[\mathrm{mg} \mathrm{g}^{-1}\right]}\end{array}$ & $\begin{array}{l}\mathrm{CV} \\
{[\%]}\end{array}$ & $\begin{array}{l}\mathrm{Ce} \\
{\left[\mathrm{mg} \mathrm{m}^{-3}\right]}\end{array}$ & $\begin{array}{l}\mathrm{x} / \mathrm{M} \\
{\left[\mathrm{mg} \mathrm{g}^{-1}\right]}\end{array}$ & $\begin{array}{l}\text { SD } \\
{\left[\mathrm{mg} \mathrm{g}^{-1}\right]}\end{array}$ & $\begin{array}{l}\mathrm{CV} \\
{[\%]}\end{array}$ & $\begin{array}{l}\mathrm{Ce} \\
{\left[\mathrm{mg} \mathrm{m}^{-3}\right]}\end{array}$ & $\begin{array}{l}\mathrm{x} / \mathrm{M} \\
{\left[\mathrm{mg} \mathrm{g}^{-1}\right]}\end{array}$ & $\begin{array}{l}\text { SD } \\
{\left[\mathrm{mg} \mathrm{g}^{-1}\right]}\end{array}$ & $\begin{array}{l}\mathrm{CV} \\
{[\%]}\end{array}$ & $\begin{array}{l}\mathrm{Ce} \\
{\left[\mathrm{mg} \mathrm{m}^{-3}\right]}\end{array}$ & $\begin{array}{l}\mathrm{x} / \mathrm{M} \\
{\left[\mathrm{mg} \mathrm{g}^{-1}\right]}\end{array}$ & $\begin{array}{l}\text { SD } \\
{\left[\mathrm{mg} \mathrm{g}^{-1}\right]}\end{array}$ & $\begin{array}{l}\mathrm{CV} \\
{[\%]}\end{array}$ \\
\hline 6.3 & 120.1 & 7.8 & 6.5 & 1.4 & 136.4 & 15.3 & 11.2 & 5.3 & 59.0 & 8.5 & 14.4 & 0.5 & 84.6 & 12.2 & 14.4 \\
\hline 50.8 & 154.3 & 22.5 & 14.6 & 9.0 & 169.8 & 17.7 & 10.4 & 9.5 & 88.7 & 5.9 & 6.7 & 0.9 & 157.4 & 8.8 & 5.6 \\
\hline 175.6 & 172.4 & 25.6 & 14.8 & 67.2 & 182.4 & 26.6 & 14.6 & 63.0 & 169.5 & 2.2 & 1.3 & 3.8 & 181.1 & 26.2 & 14.5 \\
\hline 286.8 & 173.5 & 0.2 & 0.1 & 136.6 & 197.4 & 16.4 & 8.3 & 246.5 & 193.8 & 21.6 & 11.2 & 19.3 & 237.6 & 8.1 & 3.4 \\
\hline 450.0 & 177.7 & 13.6 & 7.7 & 268.1 & 205.1 & 18.9 & 9.2 & 700.3 & 217.1 & 18.2 & 8.4 & 72.0 & 259.3 & 11.3 & 4.4 \\
\hline
\end{tabular}




\begin{tabular}{|l|l|llll} 
& & 119.7 & 265.0 & 19.5 & 7.4 \\
267.8 & 285.3 & 17.7 & 6.2 \\
\hline
\end{tabular}

\section{Table S4}

Results of the static adsorption tests performed including equilibrum concentration (Ce), adsorption capacity mean value (x/M), standard deviation (SD) amd coefficient of variation (CV) of the adsorption capacities obtained in sets of three experiments for AC4.

\begin{tabular}{|c|c|c|c|c|c|c|c|c|c|c|c|c|c|c|c|}
\hline \multicolumn{4}{|l|}{ D4 } & \multicolumn{4}{|l|}{ L2 } & \multicolumn{4}{|l|}{ Toluene } & \multicolumn{4}{|c|}{ Limonene } \\
\hline $\begin{array}{l}\mathrm{Ce} \\
{\left[\mathrm{mg} \mathrm{m}^{-3}\right]}\end{array}$ & $\begin{array}{l}\mathrm{x} / \mathrm{M} \\
{\left[\mathrm{mg} \mathrm{g}^{-1}\right]}\end{array}$ & $\begin{array}{l}\mathrm{SD} \\
{\left[\mathrm{mg} \mathrm{g}^{-1}\right]}\end{array}$ & $\begin{array}{l}\mathrm{CV} \\
{[\%]}\end{array}$ & $\begin{array}{l}\mathrm{Ce} \\
{\left[\mathrm{mg} \mathrm{m}^{-3}\right]}\end{array}$ & $\begin{array}{l}\mathrm{x} / \mathrm{M} \\
{\left[\mathrm{mg} \mathrm{g}^{-1}\right]}\end{array}$ & $\begin{array}{l}\text { SD } \\
{\left[\mathrm{mg} \mathrm{g}^{-1}\right]}\end{array}$ & $\begin{array}{l}\mathrm{CV} \\
{[\%]} \\
\end{array}$ & $\begin{array}{l}\mathrm{Ce} \\
{\left[\mathrm{mg} \mathrm{m}^{-3}\right]}\end{array}$ & $\begin{array}{l}\mathrm{x} / \mathrm{M} \\
{\left[\mathrm{mg} \mathrm{g}^{-1}\right]}\end{array}$ & $\begin{array}{l}\text { SD } \\
{\left[\mathrm{mg} \mathrm{g}^{-1}\right]}\end{array}$ & $\begin{array}{l}\mathrm{CV} \\
{[\%]}\end{array}$ & $\begin{array}{l}\mathrm{Ce} \\
{\left[\mathrm{mg} \mathrm{m}^{-3}\right]}\end{array}$ & $\begin{array}{l}\mathrm{x} / \mathrm{M} \\
{\left[\mathrm{mg} \mathrm{g}^{-1}\right]}\end{array}$ & $\begin{array}{l}\mathrm{SD} \\
{\left[\mathrm{mg} \mathrm{g}^{-1}\right]}\end{array}$ & $\begin{array}{l}\mathrm{CV} \\
{[\%]}\end{array}$ \\
\hline 0.5 & 275.1 & 29.3 & 10.6 & 10.0 & 150.0 & 6.5 & 4.3 & 0.7 & 89.2 & 11.0 & 12.3 & 0.5 & 283.0 & 16.6 & 5.9 \\
\hline 5.3 & 312.3 & 24.2 & 7.8 & 40.7 & 192.6 & 13.9 & 7.2 & 1.8 & 141.8 & 18.8 & 13.3 & 15.3 & 354.5 & 19.9 & 5.6 \\
\hline 87.7 & 341.3 & 17.7 & 5.2 & 81.8 & 233.6 & 17.9 & 7.7 & 4.9 & 202.3 & 5.0 & 2.5 & 48.0 & 372.3 & 27.9 & 7.5 \\
\hline 174.6 & 354.1 & 19.3 & 5.5 & 306.5 & 260.0 & 38.6 & 14.8 & 13.5 & 221.8 & 27.9 & 12.6 & 217.0 & 394.7 & 23.4 & 5.9 \\
\hline \multirow[t]{3}{*}{314.9} & 357.5 & 14.1 & 3.9 & 556.4 & 270.7 & 38.4 & 14.2 & 105.9 & 274.4 & 13.5 & 4.9 & 323.9 & 400.1 & 28.4 & 7.1 \\
\hline & & & & & & & & 291.5 & 303.0 & 15.3 & 5.1 & & & & \\
\hline & & & & & & & & 439.5 & 315.6 & 23.5 & 7.4 & & & & \\
\hline
\end{tabular}

\section{Table S5}

Results of the static adsorption tests performed including equilibrum concentration $(\mathrm{Ce})$, adsorption capacity mean value (x/M), standard deviation (SD) amd coefficient of variation (CV) of the adsorption capacities obtained in sets of three experiments for AC5.

\begin{tabular}{|c|c|c|c|c|c|c|c|c|c|c|c|c|c|c|c|}
\hline \multicolumn{4}{|l|}{ D4 } & \multicolumn{4}{|l|}{ L2 } & \multicolumn{4}{|l|}{ Toluene } & \multicolumn{4}{|c|}{ Limonene } \\
\hline $\begin{array}{l}\mathrm{Ce} \\
{\left[\mathrm{mg} \mathrm{m}^{-3}\right]}\end{array}$ & $\begin{array}{l}\mathrm{x} / \mathrm{M} \\
{\left[\mathrm{mg} \mathrm{g}^{-1}\right]}\end{array}$ & $\begin{array}{l}\text { SD } \\
{\left[\mathrm{mg} \mathrm{g}^{-1}\right]}\end{array}$ & $\begin{array}{l}\mathrm{CV} \\
{[\%]}\end{array}$ & $\begin{array}{l}\mathrm{Ce} \\
{\left[\mathrm{mg} \mathrm{m}^{-3}\right]}\end{array}$ & $\begin{array}{l}\mathrm{x} / \mathrm{M} \\
{\left[\mathrm{mg} \mathrm{g}^{-1}\right]}\end{array}$ & $\begin{array}{l}\text { SD } \\
{\left[\mathrm{mg} \mathrm{g}^{-1}\right]}\end{array}$ & $\begin{array}{l}\mathrm{CV} \\
{[\%]}\end{array}$ & $\begin{array}{l}\mathrm{Ce} \\
{\left[\mathrm{mg} \mathrm{m}^{-3}\right]}\end{array}$ & $\begin{array}{l}\mathrm{x} / \mathrm{M} \\
{\left[\mathrm{mg} \mathrm{g}^{-1}\right]}\end{array}$ & $\begin{array}{l}\text { SD } \\
{\left[\mathrm{mg} \mathrm{g}^{-1}\right]}\end{array}$ & $\begin{array}{l}\mathrm{CV} \\
{[\%]}\end{array}$ & $\begin{array}{l}\mathrm{Ce} \\
{\left[\mathrm{mg} \mathrm{m}^{-3}\right]}\end{array}$ & $\begin{array}{l}\mathrm{x} / \mathrm{M} \\
{\left[\mathrm{mg} \mathrm{g}^{-1}\right]}\end{array}$ & $\begin{array}{l}\mathrm{SD} \\
{\left[\mathrm{mg} \mathrm{g}^{-1}\right]}\end{array}$ & $\begin{array}{l}\mathrm{CV} \\
{[\%]}\end{array}$ \\
\hline 0.5 & 303.5 & 13.9 & 4.6 & 11.1 & 115.2 & 13.0 & 11.3 & 43.1 & 74.9 & 8.8 & 11.8 & 0.6 & 140.8 & 18.9 & 13.4 \\
\hline 1.8 & 420.2 & 50.7 & 12.1 & 51.4 & 175.7 & 1.3 & 0.8 & 84.0 & 98.5 & 13.5 & 13.7 & 1.0 & 173.9 & 2.0 & 1.1 \\
\hline 17.4 & 478.0 & 43.9 & 9.2 & 78.0 & 201.6 & 0.9 & 0.4 & 234.8 & 132.9 & 5.9 & 4.4 & 6.2 & 230.2 & 1.5 & 0.6 \\
\hline 20.2 & 496.6 & 48.1 & 9.7 & 227.9 & 260.9 & 9.8 & 3.8 & 289.3 & 145.1 & 20.4 & 14.0 & 26.4 & 283.0 & 12.0 & 4.2 \\
\hline 40.3 & 516.6 & 36.8 & 7.1 & 364.9 & 300.0 & 28.0 & 9.3 & 543.8 & 179.6 & 26.6 & 14.8 & 52.6 & 322.9 & 5.5 & 1.7 \\
\hline 203.3 & 538.0 & 35.4 & 6.6 & 438.0 & 320.0 & 11.5 & 3.6 & 718.0 & 199.1 & 14.6 & 7.3 & 121.8 & 344.8 & 0.8 & 0.2 \\
\hline 436.2 & 569.4 & 27.5 & 4.8 & & & & & & & & & 310.9 & 370.4 & 23.4 & 6.3 \\
\hline & & & & & & & & & & & & 573.5 & 402.1 & 21.3 & 5.3 \\
\hline
\end{tabular}




\section{Table S6}

Results of the static adsorption tests performed including equilibrum concentration (Ce), adsorption capacity mean value (x/M), standard deviation (SD) amd coefficient of variation (CV) of the adsorption capacities obtained in sets of three experiments for AC6.

\begin{tabular}{|c|c|c|c|c|c|c|c|c|c|c|c|c|c|c|c|}
\hline \multicolumn{4}{|l|}{ D4 } & \multicolumn{4}{|l|}{ L2 } & \multicolumn{4}{|l|}{ Toluene } & \multicolumn{4}{|c|}{ Limonene } \\
\hline $\begin{array}{l}\mathrm{Ce} \\
{\left[\mathrm{mg} \mathrm{m}^{-3}\right]}\end{array}$ & $\begin{array}{l}\mathrm{X} / \mathrm{M} \\
{\left[\mathrm{mg} \mathrm{g}^{-1}\right]}\end{array}$ & $\begin{array}{l}\text { SD } \\
{\left[\mathrm{mg} \mathrm{g}^{-1}\right]}\end{array}$ & $\begin{array}{l}\mathrm{CV} \\
{[\%]} \\
\end{array}$ & $\begin{array}{l}\mathrm{Ce} \\
{\left[\mathrm{mg} \mathrm{m}^{-3}\right]}\end{array}$ & $\begin{array}{l}\mathrm{X} / \mathrm{M} \\
{\left[\mathrm{mg} \mathrm{g}^{-1}\right]}\end{array}$ & $\begin{array}{l}\mathrm{SD} \\
{\left[\mathrm{mg} \mathrm{g}^{-1}\right]}\end{array}$ & $\begin{array}{l}\mathrm{CV} \\
{[\%]} \\
\end{array}$ & $\begin{array}{l}\mathrm{Ce} \\
{\left[\mathrm{mg} \mathrm{m}^{-3}\right]} \\
\end{array}$ & $\begin{array}{l}\mathrm{X} / \mathrm{M} \\
{\left[\mathrm{mg} \mathrm{g}^{-1}\right]}\end{array}$ & $\begin{array}{l}\text { SD } \\
{\left[\mathrm{mg} \mathrm{g}^{-1}\right]}\end{array}$ & $\begin{array}{l}\mathrm{CV} \\
{[\%]}\end{array}$ & $\begin{array}{l}\mathrm{Ce} \\
{\left[\mathrm{mg} \mathrm{m}^{-3}\right]} \\
\end{array}$ & $\begin{array}{l}\mathrm{X} / \mathrm{M} \\
{\left[\mathrm{mg} \mathrm{g}^{-1}\right]}\end{array}$ & $\begin{array}{l}\text { SD } \\
{\left[\mathrm{mg} \mathrm{g}^{-1}\right]}\end{array}$ & $\begin{array}{l}\mathrm{CV} \\
{[\%]}\end{array}$ \\
\hline 1.4 & 189.3 & 26.0 & 13.7 & 0.5 & 61.7 & 8.7 & 14.2 & 59.3 & 56.0 & 7.7 & 13.8 & 8.2 & 81.0 & 12.0 & 14.8 \\
\hline 16.3 & 203.4 & 12.3 & 6.1 & 7.9 & 81.3 & 12.1 & 14.9 & 127.7 & 83.7 & 12.0 & 14.3 & 29.1 & 126.1 & 8.3 & 6.6 \\
\hline 45.8 & 206.2 & 19.0 & 9.2 & 10.4 & 107.3 & 15.0 & 14.0 & 290.6 & 110.0 & 15.8 & 14.4 & 37.0 & 161.9 & 23.9 & 14.8 \\
\hline 63.4 & 214.3 & 30.9 & 14.4 & 70.3 & 158.8 & 23.1 & 14.5 & 822.5 & 138.3 & 20.3 & 14.7 & 283.8 & 222.7 & 30.9 & 13.9 \\
\hline 177.4 & 225.3 & 22.8 & 10.1 & 172.3 & 180.7 & 16.9 & 9.3 & & & & & 639.0 & 236.2 & 22.1 & 9.4 \\
\hline 529.9 & 232.6 & 28.1 & 12.1 & 302.1 & 196.9 & 14.0 & 7.1 & & & & & & & & \\
\hline
\end{tabular}

\section{Table S7}

Results of the static adsorption tests performed including equilibrum concentration (Ce), adsorption capacity mean value (x/M), standard deviation (SD) amd coefficient of variation (CV) of the adsorption capacities obtained in sets of three experiments for AC7.

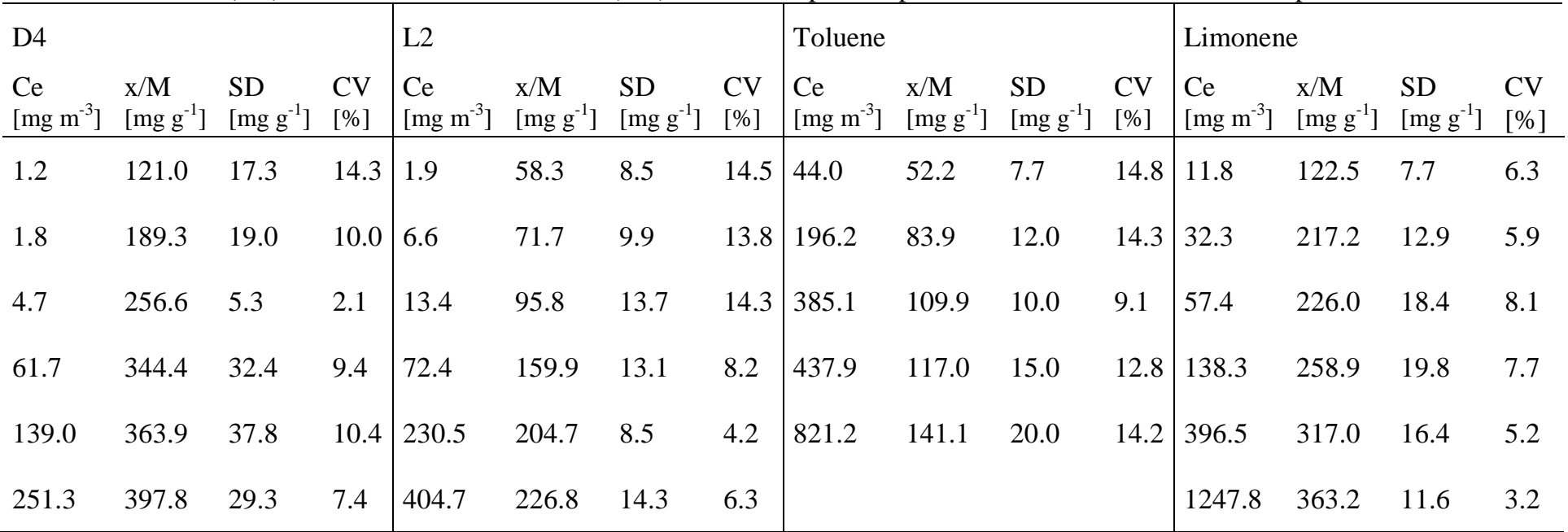

